\title{
The Elimination Effect of Take-Back Regulation on Backward Production Capacity Remanufacturing Supply Chains
}

\author{
Bangyi Li, ${ }^{1}$ Xintong Chen $\mathbb{D}^{1},{ }^{1}$ Shanting Wei, ${ }^{1}$ and Yongbo Cheng ${ }^{2}$ \\ ${ }^{1}$ College of Economics and Management, Nanjing University of Aeronautics and Astronautics, Nanjing 210016, China \\ ${ }^{2}$ School of Marketing \& Logistics Management, Nanjing University of Finance \& Economics, Nanjing 210000, China \\ Correspondence should be addressed to Xintong Chen; chenxintong@nuaa.edu.cn
}

Received 6 August 2020; Revised 18 December 2020; Accepted 2 January 2021; Published 19 January 2021

Academic Editor: Georgios I. Giannopoulos

Copyright (c) 2021 Bangyi Li et al. This is an open access article distributed under the Creative Commons Attribution License, which permits unrestricted use, distribution, and reproduction in any medium, provided the original work is properly cited.

With more and more end-of-life products in daily life, many companies are engaging in remanufacturing, including backward production capacity (BPC) enterprises. Meanwhile, take-back regulation always asks the manufacturer to take back end-of-life products to reduce pollution. However, the effect of take-back regulation on remanufacturers remains unclear. In this paper, we first analyzed the take-back regulation threshold with the elimination effect. We then discussed the impact on stakeholders, such as the manufacturer, the remanufacturer, consumers, and the government. A two-stage dynamic market model is proposed, which considers the market with/without BPC remanufacturer. Take-back regulation's elimination effect is studied, and the results show that when the collection target reaches the elimination threshold, the manufacturer's profit declines, the BPC remanufacturer is eliminated, consumer surplus decreases, and social welfare is improved. Besides, to cope with a high take-back regulation target, the manufacturer will reduce new product output, which leads to BPC remanufacturer's benefits decline. A numerical study is given with a different collecting strategy of the BPC remanufacturer, the incentive interval, the inhibition interval, and the elimination interval of the take-back regulation for stakeholders which are described. At last, some managerial insights are given to help the regulator implement take-back regulation.

\section{Introduction}

1.1. Background and Motivation. An increasing number of enterprises worldwide are willing to take back end-of-life (EOL) products and remanufacture them. The main reason is that this part of the market could be profitable for anyone in this field. The most representative example is the estimated value of the U.S. remanufacturing market of more than $\$ 43$ billion [1]. The colossal profit cake has lured many enterprises eager, including some advanced manufacturers (such as Cat Reman and Wealdstone) and Backward Production Capacity (BPC) companies. For EOL products, collectors typically have the following treatment methods: incineration, burial, recycling, dismantling, and so on. However, in the processing of EOL products, taking back and remanufacturing have become the choice of many manufacturers because of their superior economic impact and environmental protection effects. In the take-back stage, take-back includes numerous activities such as collection, transportation, and remanufacturing. And, the remanufacturing option is a more environmentally friendly way to reduce pollution and total energy consumption. That is what Mercedes-Benz does. Mercedes-Benz opens the remanufacturing industry to take back used items and sell remanufactured core components (such as motors, water pumps, and jet pumps) to consumers.

Even though companies who take back EOL products could help solve environmental issues and reuse efficiency problem, the backward production capacity remanufacturers always have two characteristics. The first one is that the production technology level is lower than the average level of the same enterprises. The second one is that pollutant emissions, energy consumption, water consumption, and other production indicators are higher than the intermediate level of the same enterprises. For example, there are many gearbox specialized companies in China. Still, some of them scamp work and stint material to produce "refurbished" products with low quality, bringing consumers risk. By using 
these "refurbished" products, consumers will be in danger. Therefore, how to reduce or even eliminate such enterprises has become the government's thorny problem. In practice, the judgment standard for backward production capacity is that an enterprise's technical level cannot meet the standard production capacity stipulated by national laws, regulations, and policies. For remanufacturing, the most noticeable regulation is take-back regulation, which imposes a collection target on the manufacturer and requires the manufacturer to take-back a certain quantity of EOL products that the manufacturer produced before.

According to previous papers, taking back EOL products is the task and the responsibility of the manufacturer [2-5]. The theory of "Extended Producer Responsibility" (EPR) put forward by Professor Lindhqvist [6] highlights that the responsibility for collecting, recycling, and final disposal of waste products belongs to the producer. Furthermore, more and more countries have adopted a series of relevant laws and regulations, requiring manufacturers to take back the products they produce. For example, the producer responsibility system in the United States [7] and the European Union [8] both show the importance that governments attach to take-back.

Under the constraints of take-back regulation, competition between manufacturer and remanufacturer is inevitable in the remanufacturing market. Whether an appropriate regulation level could eliminate BPC remanufacturers indirectly is unclear. Manufacturers may complain that high-level take-back regulation places too much burden on them [9]. However, if the level of take-back regulation reached a certain threshold and BPC remanufacturers were eliminated, would manufacturers accept this take-back regulation and support it? In this paper, we consider the take-back regulation to discuss how it destroys the BPC remanufacturers. We try to find out the manufacturer's attitude towards take-back regulation. And, we find that the manufacturer is happy to see the level of take-back regulation increasing enough to eliminate the BPC remanufacturer. What is certain is that if take-back regulation can play a role in stopping the BPC remanufacturer, this take-back regulation will inevitably change the structure of members and even products in the market. So, how the output of each product changes is another question in this paper. It is conceivable that as BPC remanufacturers are eliminated by take-back regulation, the number of remanufactured products in the market will inevitably decline. But what about the new product and the total quantity in the market? Will these changes affect market supply? As consumers participate in the market, will their benefits be affected by the level of take-back regulation? And, for the government, the final goal of market regulation is to improve social welfare. Could take-back regulation with elimination effect benefit social welfare? Different stakeholders may have various benefits [9].

\subsection{Research Questions and Significant Findings.} Although many countries have adopted the take-back regulation, in terms of its effects, several issues still need to be discovered:
(1) Whether the take-back regulation (collection target) could eliminate the BPC remanufacturer?

(2) After the BPC remanufacturer quits the market, how will the quantity of each product change?

(3) How will the collection target with the elimination effect affect the manufacturer's profit and consumer surplus?

(4) What if the BPC remanufacturer adopted a different take-back strategy?

(5) How does the collection target with the elimination effect affect social welfare?

This paper aims to solve the five questions above by conducting a game-theoretic model. To be specific, we use the Stackelberg game model in the first stage to discuss the competition relationship between the manufacturer and the BPC remanufacturer. Then, we adopt a static game model to describe the second stage. Among the findings, we show the following significant results: The take-back regulation could eliminate the BPC remanufacturer by increasing the collection target. Take-back regulation and the take-back strategy, which the BPC remanufacturer adopts, will affect product structure together. The number of remanufactured products and the total quantity always increase with the collection target. However, there will be a little change when the collection target achieves the elimination effect threshold. The manufacturer can profit from the increasing collection target after the BPC remanufacturer withdraws from the market. However, the manufacturer's profit still changes in different remanufacturing costs. Consumer surplus decreases when the collection target begins to play a role in elimination, which means the consumer may prefer a competitive market rather than a monopoly market. Social welfare keeps increasing with the collection target, but we find that social welfare suddenly rises when the collection target reaches its elimination threshold.

1.3. Contribution Statement and Paper Structure. This paper is the first study in operations management devoted to exploring the take-back regulation with elimination effect to the best of our knowledge. And, this paper is also the first study that considers a two-stage dynamic market under the take-back regulation. We attribute the main contributions of the research to the following aspects. First, we think of a market that the manufacturer coexists with the BPC remanufacturer and analyzes the two parties' optimal production decisions under the competitive relationship. From the take-back regulation perspective, we discuss the impact of the take-back regulation on BPC remanufacturer and determine the elimination effect's take-back regulation level. When the level of take-back regulation reaches a threshold, the market structure will change and the market enters the second stage (monopoly market). Second, to fully understand the elimination effect, we compare different products and stakeholders' benefits in two periods. Third, we perform an extended analysis of BPC remanufacturer's different takeback strategies, resulting in different results. We finally characterize the changes in stakeholders' benefits and divide 
the take-back regulation level into several intervals. Moreover, we distinguish the incentive, suppression, and elimination effects of stakeholders at each take-back regulation level.

The following section reviews the relevant related literature. Section 3 describes the market structure first and then introduces our competing model between a manufacturer and a BPC remanufacturer. In Section 4, we characterize the manufacturer's optimal production decision and BPC remanufacturer and then analyze the elimination effect's collection target threshold. And next, we discuss changes in new products and remanufactured products in different periods. Finally, we consider the profit of the manufacturer and compare consumer surplus. In Section 5, through a numerical study, we make an extended discussion to investigate whether a different take-back strategy of BPC remanufacturer will change the result in Section 4 . Then, we identify how social welfare changes during the collection target increasing period. At last, a conclusion is reached in Section 6. Appendix A provides all proofs in this paper.

\section{Literature Review}

Many papers study take-back regulation in the existing remanufacturing literature $[4,5,9,10]$. They studied the competition between manufacturer and remanufacturer, strategies of both parties, changes of stakeholders' benefits, and product design under the take-back regulation. They do not take the elimination effect of take-back regulation into account as we do, nor do they consider stakeholder preferences from a dynamic market perspective. For the regulation mode, there are typically three take-back regulation models: tax model $[9,11,12]$, rate model with collection target $[3,9,13]$, and rate model with collection target and reuse target $[4,7,14]$. Under the tax model, government taxes on manufacturers increase the manufacturer's costs, but some of this tax will be transferred to consumers. Thus, to ensure the manufacturer's take-back responsibility, the rate model seems more appropriate. Considering that the reuse target is not implemented in most countries in real life, this paper only takes the collection target as the research background.

Our research builds on the market competition between manufacturing and remanufacturing, where there is product differentiation, and consumer always values remanufactured products less [15-21]. Stackelberg [23] introduced a model of output leadership. The model reflects asymmetric competition among companies when, in some markets, competing enterprises' positions are not symmetrical. Asymmetry in market position causes asymmetry in decision-making order. Generally, small enterprises observe the behavior of large enterprises before deciding their own production decision. This competition model fully reflects the decision-making position between the manufacturer and the remanufacturer. Following recent work in the general supply chain management literature [23-28], as well as works in take-back regulation literature $[10,29,30]$, we model Stackelberg competition.
While the competition between manufacturer and remanufacturer has been studied from different aspects, the result does not immediately extend to the dynamic market because of the elimination effect of take-back regulation. In the remanufacturing market, the quantity of remanufactured products is always less than the number of new products. Previous research on this $[7,31-33]$ has proved that the manufacturer's production decision and remanufacturer's production decision can affect the product structure in the market. Take-back regulation could change the competitive environment and even change the number of market participants. Nevertheless, what changes will happen in other perspectives, primarily when the regulation eliminated the BPC remanufacturer, has not been discussed in the literature. This issue is the main focus of our study.

Several recent manufacturing papers [34-36] have studied backward production capacity problems. For example, Shao and Wang [35] revealed that the elimination of BPC companies would improve companies' Malmquist-Luenberger productivity index. Wang et al. [36] proved that policy regulation could help enhance the capacity of coal industries. Du and Li [34] provided Chinese industrial firm data, showing that environmental regulation can play a role in eliminating backward production capacity companies. There are also some other papers studying eliminating backward production capacity from different industries, like the energy-intensive manufacturing industry [37], coal chemical industry [38], iron and steel industry [39], and cement industry [40]. They do not capture the competition between manufacturer and remanufacturer and the battle between new products and remanufactured products, which we see in our lives, a gap this paper addresses. To the best of our knowledge, only Esenduran et al. [7] studied the two competition relationships mentioned above and the take-back regulation together. However, they have not distinguished between remanufacturers or considered changes in market structure brought by the takeback regulation as we do. Doing so will make us understand what effects may be there when the take-back regulation reaches the elimination threshold. Table 1 contains the work to date on our research gap.

\section{Model Overview}

3.1. Model Description and Notations. We consider a manufacturer that sells new products and remanufactured products in the market. A BPC remanufacturer takes back the EOL products in the market and remanufactures them, and a government is imposing take-back responsibility on the manufacturer. For the manufacturer, we use $q_{n}$ to indicate the number of new products and $q_{r 1}$ to express the number of remanufactured products. For the BPC remanufacturer, we use $q_{r 2}$ to show the number of remanufactured products. Obviously, $q_{r 1}+q_{r 2} \leq q_{n}$. As most take-back regulation literature did $[2,5,7,41]$, the government set a collection target $\beta_{c}$, which requires the manufacturer to take back at least $\beta_{c} q_{n}$ EOL product in the market. Here, we also assume that the whole collected items can be reused only once. So, $q_{r 1} \geq \beta_{c} q_{n}$. Figure 1 shows the manufacturing 
TABle 1: Overview of recent literature.

\begin{tabular}{|c|c|c|c|c|c|c|c|c|}
\hline \multirow[b]{2}{*}{ Source } & \multicolumn{2}{|c|}{ Competition } & \multicolumn{2}{|c|}{$\begin{array}{l}\text { Take-back } \\
\text { regulation }\end{array}$} & \multicolumn{2}{|c|}{ Market } & \multicolumn{2}{|c|}{$\begin{array}{l}\text { Backward } \\
\text { production } \\
\text { capacity } \\
\text { enterprises }\end{array}$} \\
\hline & Members & Products & Yes & No & Competitive & Monopoly & Yes & No \\
\hline Atasu et al. [9] & & $\sqrt{ }$ & $\sqrt{ }$ & & $\sqrt{ }$ & & & $\sqrt{ }$ \\
\hline Wang et al. [10] & & $\sqrt{ }$ & $\sqrt{ }$ & & $\sqrt{ }$ & & & $\sqrt{ }$ \\
\hline Gao et al. [12] & $\sqrt{ }$ & & & $\sqrt{ }$ & & $\sqrt{ }$ & & $\sqrt{ }$ \\
\hline Liu et al. [39] & & $\sqrt{ }$ & & $\sqrt{ }$ & & $\sqrt{ }$ & & $\sqrt{ }$ \\
\hline Wang et al. [21] & & $\sqrt{ }$ & & $\sqrt{ }$ & & $\sqrt{ }$ & & $\sqrt{ }$ \\
\hline Taleizadeh et al. [28] & $\sqrt{ }$ & & & $\sqrt{ }$ & $\sqrt{ }$ & & & $\sqrt{ }$ \\
\hline Esenduran et al. [7] & $\sqrt{ }$ & $\sqrt{ }$ & $\sqrt{ }$ & & $\sqrt{ }$ & & & $\sqrt{ }$ \\
\hline Kwak and Kim [33] & $\sqrt{ }$ & $\sqrt{ }$ & & $\sqrt{ }$ & $\sqrt{ }$ & & & $\sqrt{ }$ \\
\hline $\mathrm{Du}$ and $\mathrm{Li}[34]$ & $\sqrt{ }$ & & & $\sqrt{ }$ & $\sqrt{ }$ & & $\sqrt{ }$ & \\
\hline Wang et al. [36] & & $\sqrt{ }$ & & $\sqrt{ }$ & $\sqrt{ }$ & & $\sqrt{ }$ & \\
\hline This paper & $\sqrt{ }$ & $\sqrt{ }$ & $\sqrt{ }$ & & $\sqrt{ }$ & $\sqrt{ }$ & $\sqrt{ }$ & \\
\hline
\end{tabular}

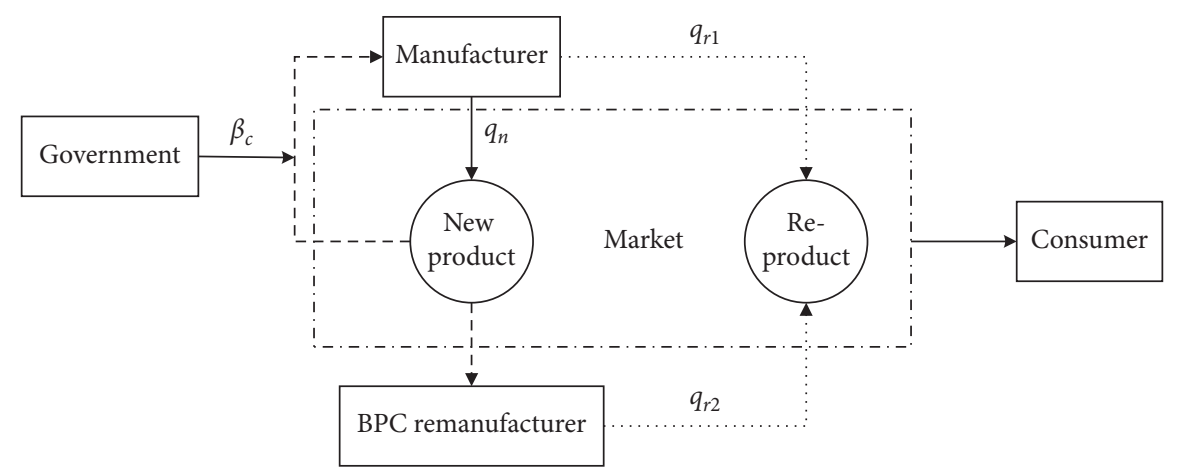

\footnotetext{
$\longrightarrow$ Manufacturing process

$\rightarrow$ Taking-back process

. Remanufacturing process
}

FIgURE 1: The structure of the investigated market.

process, taking-back process, and remanufacturing process. Moreover, all notations can be found in Table 2 .

3.2. Assumptions. In this paper, we consider that consumers have their preferences for new products and remanufactured products [42]. They can choose to buy new products or remanufactured products by themselves, and they will select one of the options to maximize their utility. Let us assume that consumers' price perception for new products is $v$, and we normalize this price perception to $[0,1]$. So, the consumer's utility of a new product $U_{n}=v-p_{n}$. For the remanufactured product, the consumer thinks that new products and remanufactured products are not equivalent. Therefore, when the consumer is buying a remanufactured product, the consumer often values it less. Let us assume that consumers' price perception for the remanufactured product is $\alpha v[31,43-45]$, where $\alpha \in(0,1)$. So, the consumer's utility of a remanufactured product $U_{r}=\alpha v-p_{r}$.

We assume the product demand is in a single cycle. This cycle has characteristics like the product's price, and output is steady and governmental regulation (collection target) will not change. This assumption is widely used in take-back legislation and remanufacturing literature [44-47]. Then, according to the quantities of different products, we can have a new product's price and a remanufactured product's price as follows: $p_{n}=1-q_{n}-\alpha\left(q_{r 1}+q_{r 2}\right) ; \quad p_{r}=\alpha\left(1-q_{n}-\right.$ $\left.q_{r 1}-q_{r 2}\right)$.

3.3. Model. Then, we describe the problem that the manufacturer faces under the take-back regulation mode. There is a manufacturing $\cos t c_{n}$ for each unit of the new product for the manufacturer, and each remanufacturing cost is $c_{r 1}$. To reflect the cost advantage of remanufacturing, we set $c_{r 1}<c_{n}$. Next, we give out the problem formulation to the manufacturer and the BPC remanufacturer:

$$
\begin{aligned}
& \underset{q_{n}, q_{r 1}}{\operatorname{Max}} \Pi_{1}=\left(p_{n}-c_{n}\right) q_{n}+\left(p_{r}-c_{r 1}\right) q_{r 1} \\
& \text { s.t. } \beta_{c} q_{n} \leq q_{r 1} \leq q_{n} .
\end{aligned}
$$

The manufacturer maximizes the profit from selling new and remanufactured products. Under the take-back regulation, the manufacturer needs to take-back at least $100 \beta_{c}$ percent of the new products which are end-of-life. However, the maximum taking back items would not exceed the total 
TABLE 2: Summary of notations.

\begin{tabular}{|c|c|}
\hline \multicolumn{2}{|l|}{ Parameters } \\
\hline$c_{n}$ & Manufacturer's unit cost of new product $(\$)$ \\
\hline$c_{r 1}$ & Manufacturer's unit cost of the remanufactured product $(\$)$ \\
\hline$c_{r 2}$ & BPC remanufacturer's unit cost of the remanufactured product $(\$)$ \\
\hline$\alpha$ & Consumer's valuation for remanufactured products as a fraction of valuation for new products (\%) \\
\hline$\beta_{c}$ & Collection target $(\%)$ \\
\hline \multicolumn{2}{|c|}{ Decision variables } \\
\hline$q_{n}$ & Quantity of new products \\
\hline$q_{r 1}$ & Manufacturer's quantity of remanufactured products \\
\hline$q_{r 2}$ & BPC remanufacturer's quantity of remanufactured products \\
\hline$p_{n}$ & The unit price of new products $(\$)$ \\
\hline$p_{r}$ & The unit price of remanufactured products $(\$)$ \\
\hline \multicolumn{2}{|l|}{ Objectives } \\
\hline$\Pi_{1}$ & Profit of manufacturer $(\$)$ \\
\hline$\Pi_{2}$ & Profit of BPC remanufacturer $(\$)$ \\
\hline $\mathrm{CS}$ & Consumer surplus $(\$)$ \\
\hline SW & Social welfare $(\$)$ \\
\hline
\end{tabular}

quantity of new products. The constraint above captures this, ensuring that the number of remanufactured products would not exceed the manufacturer's availability.

Next, we define the BPC remanufacturer's problem. For the BPC remanufacturer, there is a remanufacturing cost $c_{r 2}$ for each unit of remanufactured product. Because of the low production technology we can have $c_{r 2}>c_{r 1}$. Regardless of the collection target, BPC remanufacturer's problem is as follows:

$$
\begin{aligned}
& \underset{q_{r 2}}{\operatorname{Max}} \Pi_{2}=\left(p_{r}-c_{r 2}\right) q_{r 2} \\
& \text { s.t. } 0 \leq q_{r 2} \leq q_{n}-q_{r 1} .
\end{aligned}
$$

The BPC remanufacturer maximizes the profit from selling remanufactured products. We noticed that the BPC remanufacturer is a follower in the market. The rest of the EOL products will determine the maximum quantity of taking back in the market after the manufacturer takes back. Because the take-back regulation always does not impose obligations on the remanufacturer, the BPC companies in this paper will not have a minimum taking-back quantity. The constraint above captures these, ensuring that the number of remanufactured products would not exceed the BPC remanufacturer's availability.

Because there is a decision order between the manufacturer and the BPC remanufacturer, we will use the Stackelberg game model to analyze, through solving the firstorder conditions on the Lagrange function. We use superscript $*$ to represent the optimal values of the model.

\section{Analysis}

In this section, we first give out the optimal production decisions of the manufacturer and BPC remanufacturer. Then, we discuss when the collection target with elimination could happen. After that, we analyze the market without the BPC remanufacturer and compare each perspective's benefits, like the number of new products, number of remanufactured products, manufacturer's profit, and consumer surplus.
4.1. Solution Methodology. We use the Stackelberg game to solve the manufacturer's problems and the BPC remanufacturer in the competitive market. This game model can directly reflect two parties' relationship (who is the leader and the follower). As described in Section 3.3, the manufacturer is the leader in the market, and the BPC remanufacturer is the follower who will decide on the manufacturer. So, as the Stackelberg game's reverse solution method, we should calculate the BPC remanufacturer's optimal decision and then solve the manufacturer's problem. However, after the BPC is eliminated, the manufacturer's question becomes a static game, and he only considers his own decision.

4.2. Competitive Market with BPC Remanufacturer. In a competitive market, there are two competing relationships. One is the competitive relationship between new and remanufactured products. The other one is the competitive relationship between manufacturer and remanufacturer because they both sell remanufactured products. According to the decision order mentioned above, we first characterize the equilibrium in this competitive market.

Proposition 1. If the manufacturer chooses to take back the following regulated collection target in the competitive market, his optimal production decision is $q_{n}^{*}=\left(\left(1-c_{n}-c_{r 1} \beta_{c}+\alpha \beta_{c}\right) /\left(2\left(1+\alpha+2 \alpha \beta_{c}\right)\right)\right), q_{r 1}^{*}=\beta_{c} q_{n}^{*}$.

Proposition 1 shows that, for the manufacturer, the quantity of new products is not only affected by the unit cost of the new products but also by the unit cost of the remanufactured products. As we can see that $\left(\partial q_{n}^{*} / \partial c_{r 1}\right)<0$, if the manufacturer's unit cost of the remanufactured product rises, he will choose to reduce the output of the new product because $q_{r 1}$ will change with $q_{n}$ and high $q_{r 1}$ will increase his remanufacturing costs. However, we have not taken the situation when the manufacturer takes back EOL products voluntarily. At that time, the manufacturer finds that remanufacturing is profitable, and the collection target will not achieve the purpose of regulating the manufacturer's behavior. On the other hand, the manufacturer's voluntary 
taking back behavior is what the government wants. So, in this paper, we only discuss the manufacturer's action related to the regulation.

Proposition 2. If the BPC remanufacturer chooses to take back all rest of EOL products to remanufacture in the competitive market, his optimal production decision is $q_{r 2}^{*}=\left(1-\beta_{c}\right)\left(\left(1-c_{n}-c_{r 1} \beta_{c}+\alpha \beta_{c}\right) /\left(2\left(1+\alpha+2 \alpha \beta_{c}\right)\right)\right)$.

From Proposition 2, we can easily find that the optimal value $q_{r 2}$ is always related to the collection target. The proposition reflects that the regulated collection target affects the manufacturer and impacts the BPC remanufacturer's behavior. This result makes it possible for the government to eliminate BPC remanufacturer through the regulation method. However, Proposition 2 has not considered that the BPC remanufacturer will choose a part of the rest of the EOL products in the market. We will take this situation as a further discussion in Section 5 to see whether the regulation can still work.

We can also see that $q_{r 2} \geq 0$. Therefore, if the government tries to eliminate the BPC remanufacturer, the government needs to set a particular collection target to make his profit turn 0 or less. According to this idea, we can have a proposition like below:

Proposition 3. In the competitive market, regulated collection target could have an elimination effect if, in equilibrium,

(i) $c_{r 2}>\max \left\{\left(\left(c_{r 1}+\alpha\right) / 2\right),\left(\left(\alpha\left(c_{n}+\alpha\right)\right) /(1+\alpha)\right)\right\}$, the collection target always has an elimination effect.

(ii) $\max \left\{c_{r 1},\left(\left(\alpha\left(c_{n}+\alpha\right)\right) /(1+\alpha)\right)\right\}<c_{r 2} \leq\left(\left(c_{r 1}+\alpha\right) / 2\right)$, the collection target can have an elimination effect when $\beta_{c}>\beta_{c}^{+}$, where $\beta_{c}^{+}=\left(\left(\alpha\left(c_{n}+\alpha\right)-(1+\right.\right.$ $\left.\left.\alpha) c_{r 2}\right) /\left(2 c_{r 2}-\alpha-c_{r 1}\right)\right)$

(iii) $\max \left\{c_{r 1},\left(\left(c_{r 1}+\alpha\right) / 2\right)\right\}<c_{r 2} \leq\left(\left(\alpha\left(c_{n}+\alpha\right)\right) /(1+\alpha)\right)$, the collection target can have an elimination effect when $\beta_{c}>\beta_{c}^{+}$.

Proposition 3 lists three situations that the collection target can reach the elimination goal. However, there is another method, which is $\beta_{c}=1$. While the government imposes a $100 \%$ take-back rate on the manufacturer, the BPC remanufacturer will have no EOL products to collect. Indeed, it is a direct way to clear the market, but it puts too much burden on the manufacturer. This method is not conducive to the production enthusiasm of the manufacturer. Therefore, this strategy will not work in real life. Also, case (i) in Proposition 3 shows that the higher the remanufacturing cost of the BPC remanufacturer, the more pronounced the takeback regulation's elimination effect. Besides, case (ii) of Proposition 3 implies the manufacturer's remanufacturing cost relationship: $\quad c_{r 1}>\left(2 \alpha\left(c_{n}+\alpha\right) /(1+\alpha)-\alpha\right)$, which means two praties' remanufacturing costs are similar, so a high-level take-back regulation target is required to restrain the BPC remanufacturer. Moreover, the implicit condition of (iii) in Proposition 3 is $c_{r 1}<\min \left\{\left(\left(2 \alpha\left(c_{n}+\alpha\right)\right) /(1+\alpha)\right)-\alpha\right.$, $\left.\left(\left(\alpha\left(c_{n}+\alpha\right)\right) /(1+\alpha)\right)\right\}$ that the manufacturer remanufacturing has cost advantages, and a low-level take-back regulation target can also eliminate the BPC remanufacturer. If a high take-back regulation target is imposed on the manufacturer, his profit will decline, which indirectly increases the BPC remanufacturer's gain. Therefore, when the government implements the take-back regulation, it is necessary to prevent such situations from occurring, not that the higher the takeback regulation target, the better.

4.3. Manufacturer's Perspective. As the government imposes a collection target with elimination, the market will enter a new stage: a monopoly market, where there is only one manufacturer. A competitive market turns out to be a monopoly market. In the monopoly market, many things change. Next, we will discuss the changes for each party's benefit.

4.3.1. New Products and Remanufactured Products. This section analyzes the manufacturer's profit and sees whether the collection target with elimination can benefit him after the BPC remanufacturer quit the market. First, we give out the optimal production decision of the manufacturer in the monopoly market.

Proposition 4. In the monopoly market, the manufacturer's optimal production decision is $q_{n}^{*}=\left(\left(1-c_{n}-c_{r 1}\right.\right.$ $\left.\left.\beta_{c}+\alpha \beta_{c}\right) /\left(2+2 \alpha \beta_{c}\left(2+\beta_{c}\right)\right)\right), q_{r}^{\prime *}=\beta_{c} q_{n}^{\prime *}$.

Proposition 4 is similar to Proposition 1; the little difference is the denominator. Moreover, it is easy to find that $2\left(1+\alpha+2 \alpha \beta_{c}\right)>2+2 \alpha \beta_{c}\left(2+\beta_{c}\right)$, so $q_{n}{ }^{*}>q_{n}^{*}$. Hence, we can have an extended proposition like below:

Proposition 5. In the competitive market, if the BPC remanufacturer chooses to take back all the rest of the EOL products in the market, the regulated collection target with the elimination effect will have a positive incentive effect on the production of new products.

Proposition 5 shows that, as long as the collection target reaches its elimination effect, the number of new products will rise immediately. That is because there is no competitor in the remanufacturing market. Less remanufactured products in the market mean that the remanufactured product's price will be higher than before. The manufacturer finds it profitable in remanufacturing. Large taking back quantity brings many profits. So, the manufacturer produces more new products into the market for the next stage to take back. Meanwhile, the amount of remanufactured products also changes after the market changes.

Proposition 6. In the competitive market, if the BPC remanufacturer chooses to take back all the rest of the EOL products in the market, the regulated collection target with the elimination effect will have a negative inhibitory impact on the production of the remanufactured product.

Proposition 6 indicates that, although the collection target has been improved, the number of remanufactured products is still decreasing due to eliminating the BPC remanufacturer. However, we can find that the remanufactured product's quality has been improved, because all remanufactured products are provided by the manufacturer 
now. The management implication here is that the government could raise the collection target's level to ensure the remanufactured product's quality.

4.3.2. Profit of the Manufacturer. The change in product output may not cause the manufacturer to pay much attention because he always defines his gain and loss standards as the increase or decrease in profits. Therefore, we discuss the changes in the manufacturer's profit after eliminating BPC remanufacturer.

Proposition 7. Suppose in the competitive market, the BPC remanufacturer chooses to take back all the rest of EOL products. In that case, the regulated collection target with the elimination effect will improve the manufacturer's profit.

Proposition 7 shows that the manufacturer can get more profit after the BPC remanufacturer quits the market. Hence, the collection target with the elimination effect, on the one hand, increases the manufacturer's responsibility for taking back. Still, on the other hand, it increases the profit of the manufacturer. Overall, the manufacturer agrees with the government and prefers this change.

4.4. Consumer Perspective. We have discussed the manufacturer's perspective above and know that the collection target with the elimination could benefit the manufacturer. Nevertheless, it is not necessarily correct from the consumer's perspective. While it is evident that the high collection will put pressure on the manufacturer, especially remanufacturing costs, this will cause the manufacturer to pass some of his expenses to consumers indirectly by increasing product price, which will decrease consumer surplus. To comprehend the collection target's full effect, we must examine this issue to see how consumer changes after the BPC remanufacturer are eliminated.

The total consumer surplus consists of two parts: the first part is brought by new products whose utility is $v-p_{n}$. The remanufactured products carry the second part of it that the consumer values less and its utility is $\alpha v-p_{r}$ (as shown in Figure 2). The formulation of consumer surplus is shown as follows:

$$
\mathrm{CS}=\int_{\left(\left(p_{n}-p_{r}\right) /(1-\alpha)\right)}\left(v-p_{n}\right) \mathrm{d} v+\int_{p_{r} / \alpha}^{\left(\left(p_{n}-p_{r}\right) /(1-\alpha)\right)}\left(\alpha v-p_{r}\right) \mathrm{d} v
$$

Proposition 8. The collection target with the elimination effect will decrease the total consumer surplus.

Proposition 8 shows that consumer surplus can be higher in the competitive market. In the competitive market, two competitors are remanufacturing, which means the number of remanufactured products will be higher than in the monopoly market. The remanufactured product price could be lower, which can increase consumer utility in a remanufactured product. Moreover, at the same time, in the competitive market, the collection target is soft, so the quantity of new products is also higher than that in the

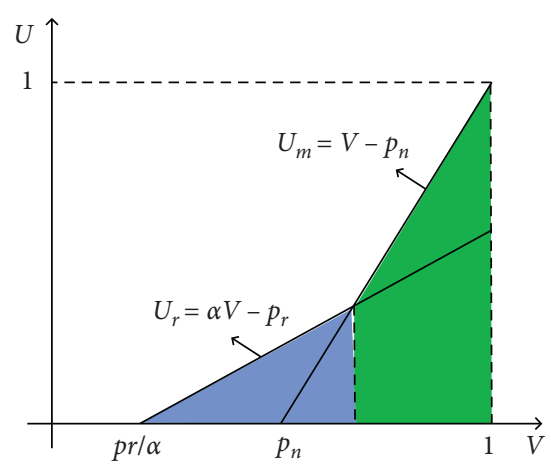

Figure 2: Consumer surplus.

monopoly market. Consumer utility in new products also can be higher than that in the monopoly market.

\section{Numerical Study}

This section first gives out the BPC remanufacturer's profit through a numerical study to show how the collection target makes him quit the market. Next, we compare the number of various products on the market. Then, we create an extended discussion to analyze whether a different BPC remanufacturer strategy could change the benefit of most perspectives. Finally, we take a look at social welfare from the government perspective to see what changes the collection target with the elimination effect will bring to social welfare. Here, we take the cell phone as an example to represent the product required to be taken back and remanufactured. For the cost of products [48], we choose $c_{n}=0.35$ as the cost of the new product; $c_{r 1}=0.25 c_{n}, 0.5 c_{n}$ to show the manufacturer's low and high remanufacturing cost. Furthermore, we consider that $\alpha=0.6$ is the valuation in new product and remanufactured product. We list the data input (Table 3 ) and objectives output (Table 4) below to show the collection target with elimination effect:

Our observations still hold when the remanufactured product's valuation is low and high. However, we only take cell phone as a study case in this section and use the cell phone industry parameters, so our observations may not represent other industries.

5.1. Profit of BPC Remanufacturer. According to the analysis above, we know that, in the competitive market, BPC remanufacturer's remanufactured product output is always positive, and the collection target can affect his profit if he chooses to take back all rest of EOL products in the market. Here, we give out the profit of BPC remanufacturer with different remanufacturing costs. Moreover, let us see when the $\mathrm{BPC}$ remanufacturer gain turns to 0 as the collection target increases.

Figure 3 shows that the BPC remanufacturer's profit decreases with the increase of the collection target. When his remanufacturing cost is high enough, the collection target begins to play the role of eliminating. This phenomenon is because the formulation of BPC remanufacturer's profit decreases with the collection target. Furthermore, with the 
TABle 3: Data input.

\begin{tabular}{lc}
\hline Parameter & Value \\
\hline$c_{n}$ & 0.35 \\
$c_{r 1}$ & $0.25 c_{n}$ \\
$c_{r 2}$ & 0.354 \\
$\alpha$ & 0.6 \\
$\beta_{c}$ & 0.4 \\
\hline
\end{tabular}

TABLE 4: Objective output.

\begin{tabular}{lcc}
\hline Objectives & Competitive market & Monopoly market \\
\hline$q_{n}$ & 0.205038 & 0.284211 \\
$q_{r 1}$ & 0.0615115 & 0.143527 \\
$q_{r 2}$ & 0.0852634 & - \\
$p_{n}$ & 0.671939 & 0.66463 \\
$p_{r}$ & 0.353954 & 0.378315 \\
$\Pi_{1}$ & 0.0823998 & 0.114217 \\
$\Pi_{2}$ & $-6.59052 \times 10^{-6}$ & - \\
\hline
\end{tabular}

increasing collection target, the manufacturer will decrease his new product to make his collecting task decline, reducing the BPC remanufacturer's collecting and profit. Figure 3 verifies Proposition 3 and proves that, when the remanufacturing cost of BPC remanufacturer is low, the collection target will have no elimination effect. And, this has been mentioned above in Section 4 already.

The managerial implications for the remanufacturer are as follows: (1) trying his best to low down remanufacturing cost (such as introducing advanced equipment and upgrade the original production line); (2) cooperating with the manufacturer (such as obtaining the manufacturer's remanufacturing technology license) to reduce remanufacturing cost.

5.2. Product Analysis. In Section 5.1, it is mentioned that the number of new products would rise and the number of remanufactured products would decrease. However, we still have not discussed how the total quantity changes in different markets and how the quantities of different types of products change in the monopoly market if BPC remanufacturer chooses to take back all EOL products.

As shown in Figure 4 above, the output of new products and the remanufactured products are relatively stable in the competitive market. However, after the BPC remanufacturer was eliminated, the number of new products has increased. However, with the improvement of the regulated collection target, new products' output has gradually decreased. This result is because the manufacturer is facing more responsibility for taking back. By reducing the output of new products, the manufacturer can reduce his taking back items and indirectly reduce his collecting fees and remanufacturing costs.

In contrast, as the collection target level improves, the number of remanufactured products in the monopoly market always increases. The reason for this is that the manufacturer needs to collect more items to achieve a high collection target, so, to make full use of collected products, the manufacturer will try his best to reuse, which leads the number of remanufactured products to grow. From the perspective of the total quantity of products in the market, the elimination of BPC remanufacturer results in a reduction in the market's total quantity. Moreover, we have mentioned that the manufacturer will reduce new products to cope with the high collection target, but the total quantity is still growing. This consequence is because the quantity of remanufactured products increases, and the increment of remanufactured products is higher than the decline of new products.

5.3. Different Strategy from BPC Remanufacturer. In the previous analysis, the BPC remanufacturer's take-back strategy in the competitive market was considered "taking back all rest EOL products in the market." However, when the BPC remanufacturer chose to take back part $0<q_{r 2}<\left(1-\beta_{c}\right) q_{n}$, the effects of collection target with elimination effect have not yet been discussed. Here, we consider it as an extended discussion.

Figure 5 shows that the collection target can affect BPC remanufacturer's product, and we consider the elimination effect from this perspective. That is because, in this situation, the optimal production decision of BPC remanufacturer will not always exist. However, in his profit formulation, we also can see that its formulation is always positive. So, when the $\mathrm{BPC}$ remanufacturer chooses to take back some of the rest EOL products in the market, we should consider his remanufactured products' output. The reason for elimination in Figure 5 is that the high collection target leads the manufacturer's remanufactured products increase. However, the manufacturer's remanufacturing cost is lower than his competitor's, so BPC remanufacturer's market competitiveness decreases. The manufacturer will gradually occupy the whole market with low cost and high output.

In Figure 5, we also can find that, when the remanufacturing cost of BPC remanufacturer is high, the collection target's elimination effect still exists. The higher the remanufacturing cost, the lower the minimum collection target with the elimination effect.

As shown in Figure 6, the quantity of new products is always declining, while remanufactured products are generally rising. The reason for the new product's decline has been discussed before, and Figure 5 shows that BPC remanufacturer's remanufactured products always decrease with the collection target. So, the only explanation for the total quantity of remanufactured products growing is that the manufacturer's remanufactured product increases. Though the manufacturer attempts to reduce the new product's output to make his collection task easy, the increasing rate of the collection target is higher than the decreasing rate of the new product, which leads the total quantity of remanufactured products to grow with the collection target. During the first and second stages of transition, BPC remanufacturer was eliminated from the market. The number of remanufactured products has declined, but in the second stage of a monopoly market, the manufacturer has expanded the remanufactured products' production due to the increase in the collection target. 


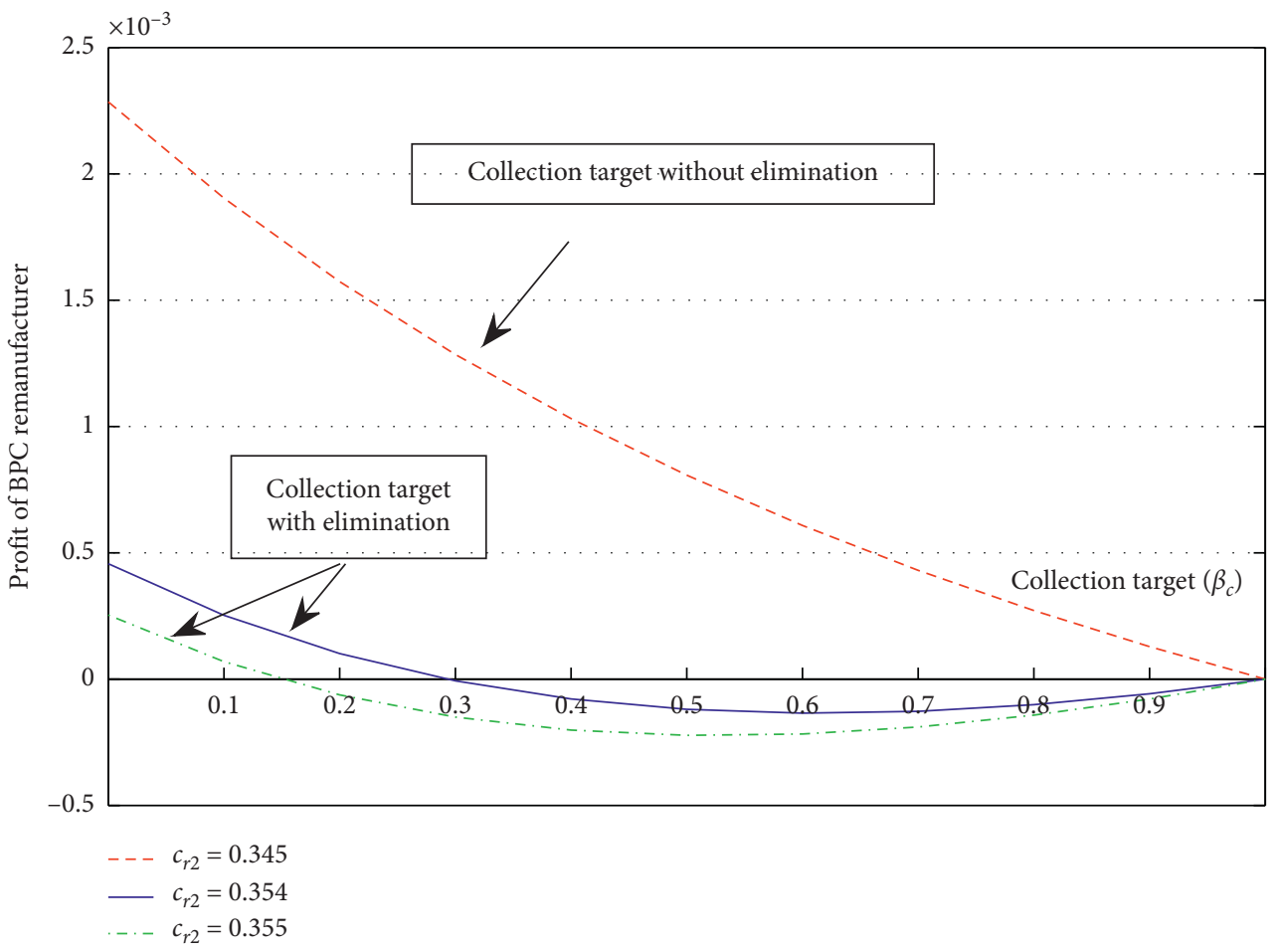

FIgURE 3: Profit of BPC remanufacturer.

However, in terms of the total quantity of products in the market, the number of total products in the second-stage monopoly market is lower than the total quantity of products in the first-stage competitive market. It can be seen that competition can stimulate production, especially the output of new products.

However, we should also notice that, compared with Figure 4, the BPC remanufacturer's take-back strategy has affected the first stage's market structure. In the first stage, if the BPC remanufacturer chooses to take back all the rest EOL products in the market, the quantity of new products is 0.205 , and the quantity of remanufactured products is 0.205 . The total quantity of products is 0.41 . The output of each product is stable. However, suppose the BPC remanufacturer chooses to take back part of the rest of EOL products in the market. In that case, the quantity of new products is $0.37-0.35$, the quantity of remanufactured products is $0.04-0.07$, and the total quantity of products is 0.4-0.43. It is evident that BPC remanufacturer's take-back strategy affects the market structure and affects the total quantity in the market. Furthermore, we give out our observations as follows:

Observation 1. The strategy of BPC remanufacturer can affect the structure of the market in the competitive market. If BPC remanufacturer chose to take back all rest of EOL products, the new products' output and the output of remanufactured products are relatively stable. Otherwise, the new product's output (remanufactured product) will decrease (increase) with the collection target. And the total quantity in the market will increase concerning the collection target.
Figure 7 shows that the profit of the manufacturer performs differently under different remanufacturing costs. As can be seen in Figure 7(a), when the manufacturer's remanufacturing cost is low, the profit increases with the collection target. Because at this time, the manufacturer finds remanufacturing is profitable, and he is willing to collect and reuse the EOL products. Therefore, the profit of the manufacturer is always growing. However, in Figure 7(b), the manufacturer's profit first increases with the collection target in the first stage because of the high remanufacturing cost but decreases in the second stage. This change also indicates that competition may lead the manufacturer to get many profits under take-back regulation, especially when his remanufacturing cost is high. Based on the two figures, the manufacturer's profit is always higher in the second stage, where the market is a monopoly market. This result is because the manufacturer occupies the whole market. Though the total output of products in the market is less than in the competitive market, the manufacturer will raise products' prices to gain more profit, especially there is no competitor.

Figure 8 shows that consumer surplus can increase with the collection target in each stage. This phenomenon indicates that the collection target is usually friendly to the consumer. However, we can also find that consumer surplus in the second stage is always lower than in the first stage, consistent with Proposition 8. In the first stage, the BPC remanufacturer competing with the manufacturer makes products' prices low, which benefits the consumer. However, after BPC remanufacturer quits the market, the manufacturer raises prices to sell, making consumer surplus decline. From here, we can see that consumers always prefer a competitive market where the BPC remanufacturer exists. 


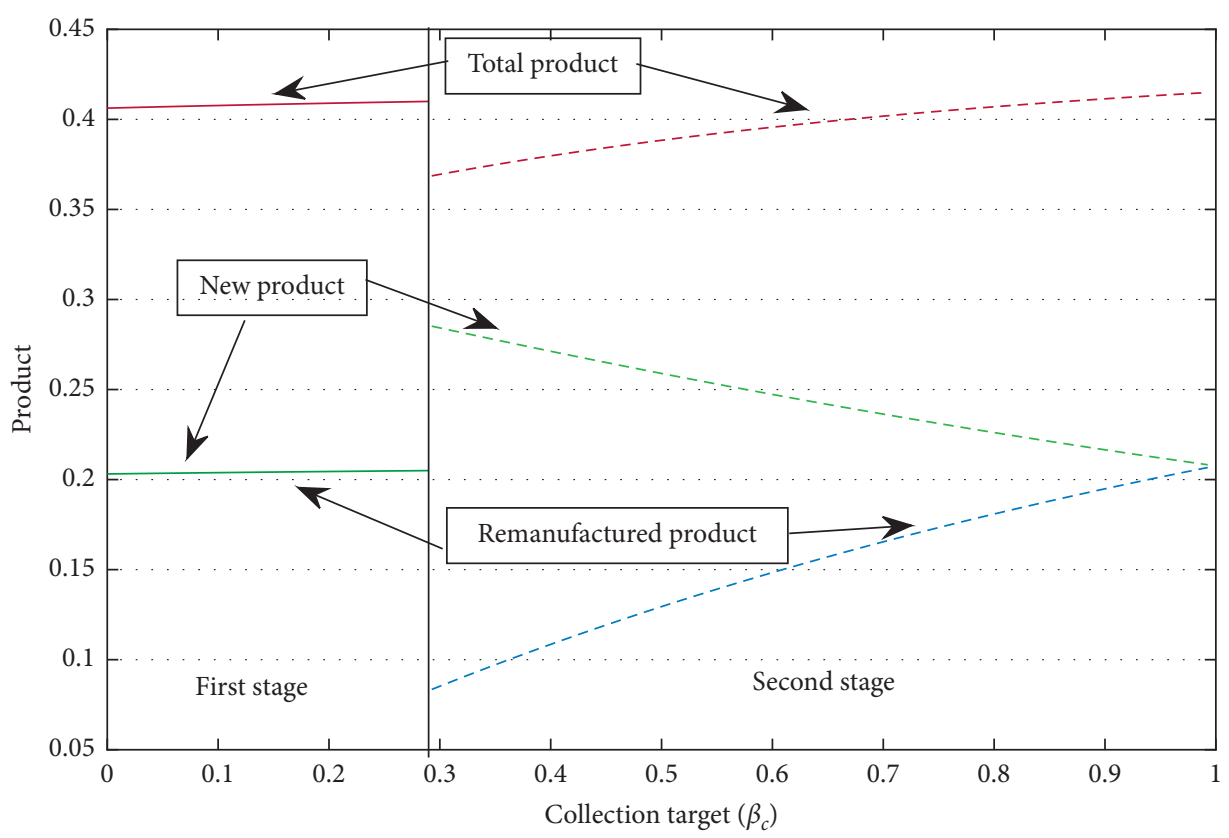

FIgURE 4: Changes in the quantities.

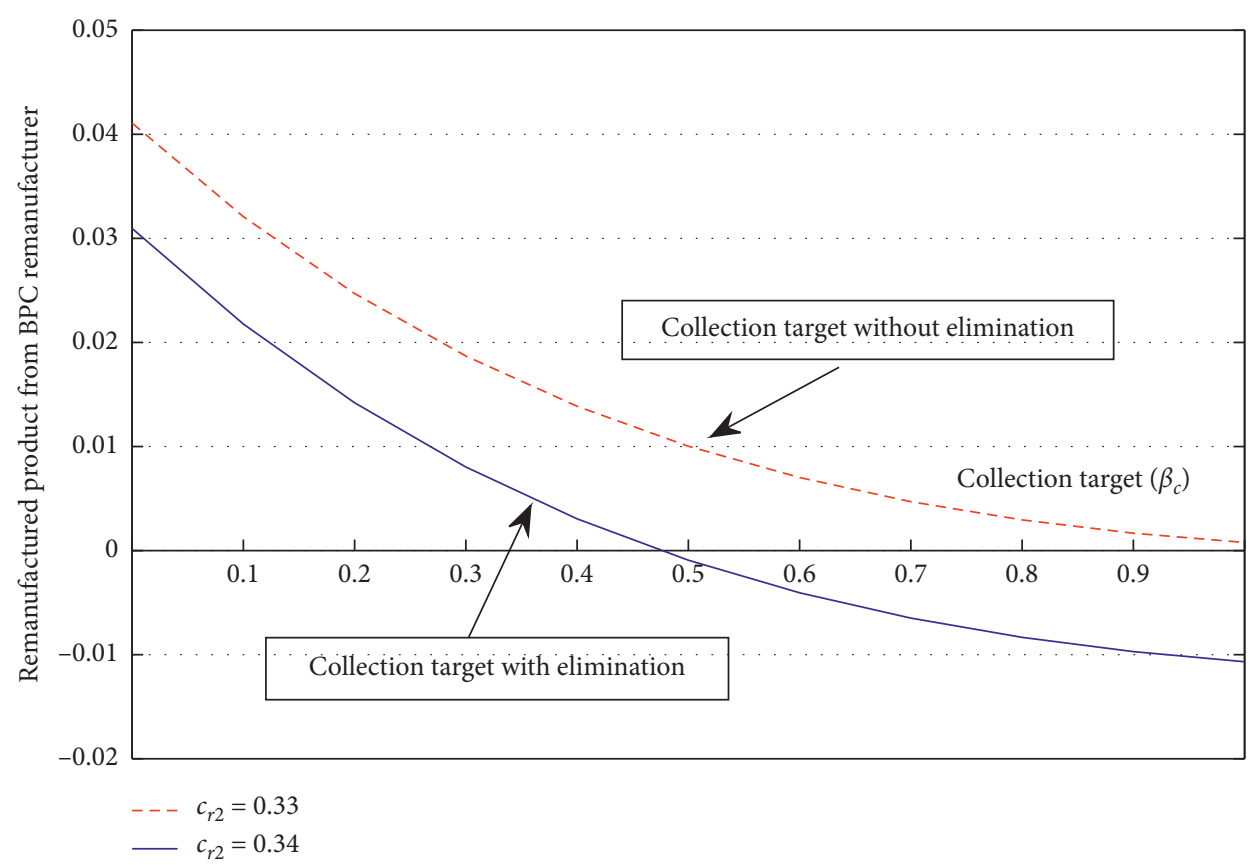

FIGURE 5: Remanufactured products from BPC remanufacturer.

Whether the consumer plays a role in protecting the BPC remanufacturer is still unknown. However, we should notice that the government's guidance and incentives are needed when the consumer enters a monopoly market.

5.4. Social Welfare. Our analysis so far has discussed the changes in the new products, remanufactured products, manufacturer's profit, and consumer surplus. However, we have not yet investigated social welfare from the government perspective. Following the previous literature [46, 47], we define the social welfare in the competitive market as the sum of the manufacturer's profit $\left(\prod_{1}\right), \mathrm{BPC}$ remanufacturer's profit $\left(\prod_{2}\right)$, consumer surplus $(C S)$, and environmental pollution $(E)$ :

$$
\mathrm{SW}_{1}=\Pi_{1}+\Pi_{2}+\mathrm{CS}-E .
$$

Regardless of the BPC remanufacturer's take-back strategy, the elimination effect will be reflected when the regulated collection target reaches a certain threshold. So, the social welfare will immediately turn to the second stage 


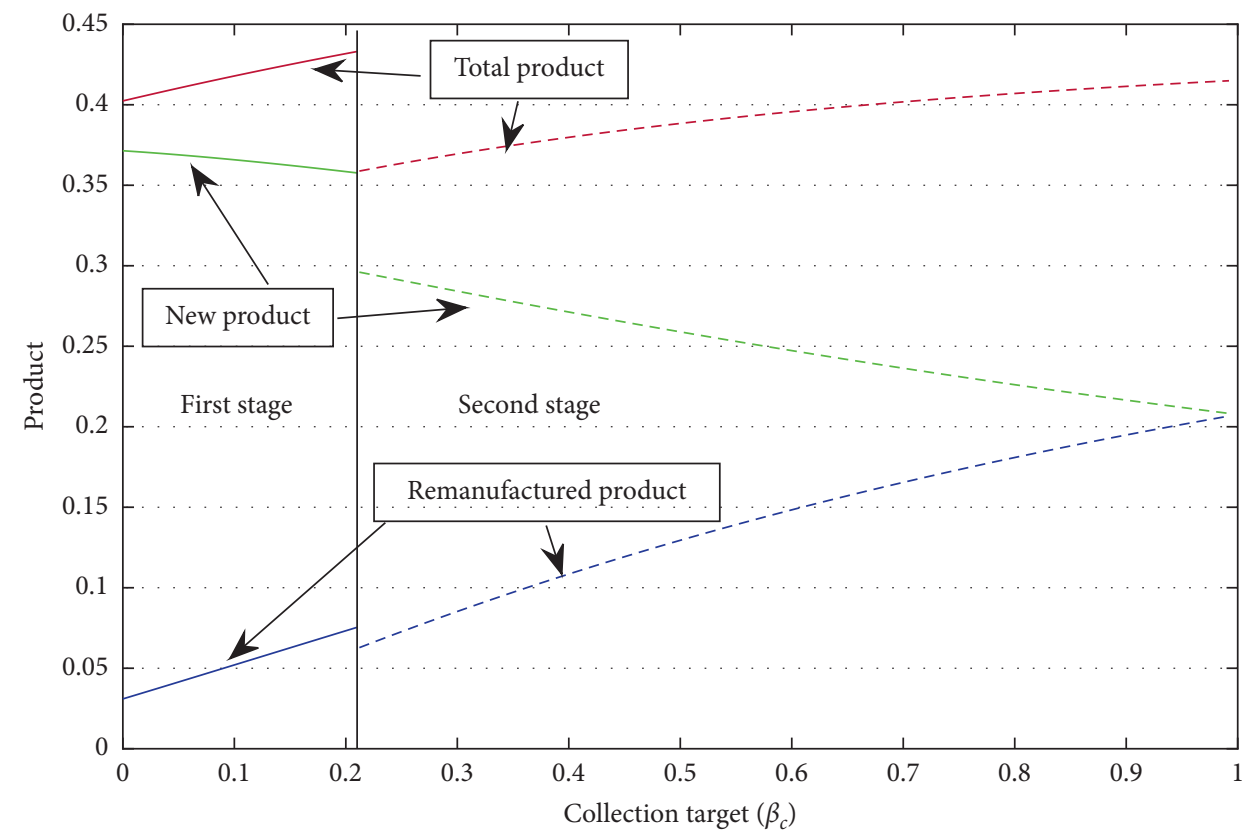

FIGURE 6: Changes of each type of product under different strategies from the BPC remanufacturer.

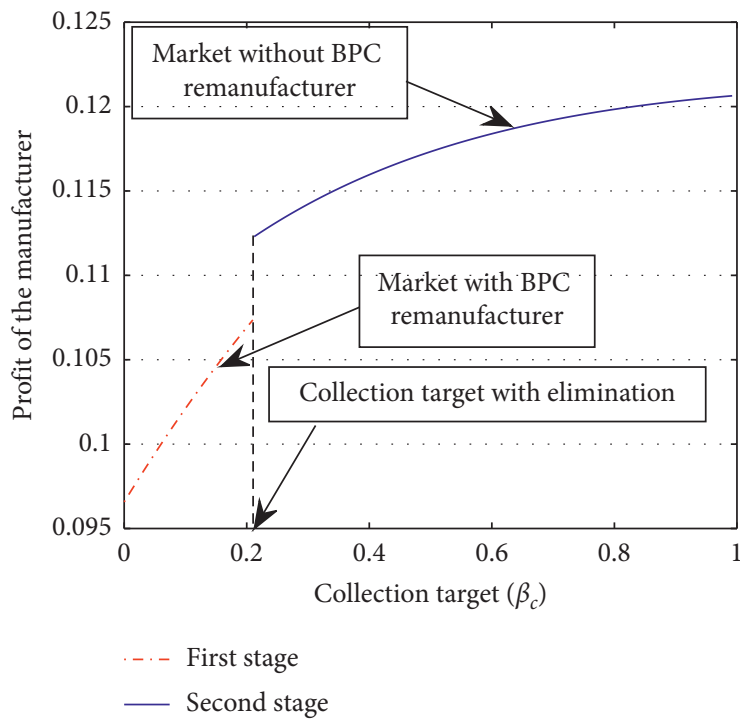

(a)

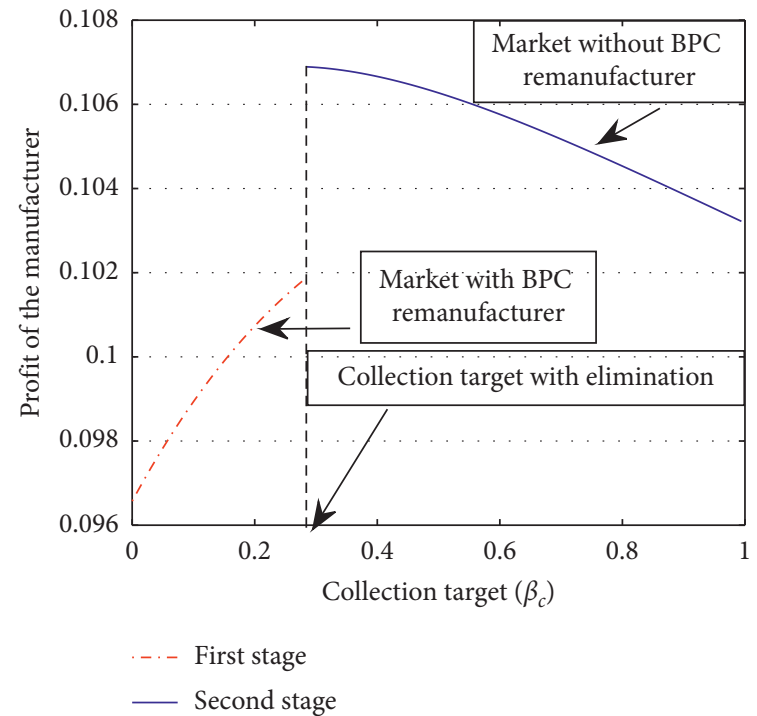

(b)

FIgURE 7: Profit of the manufacturer under different remanufacturing costs. (a) $c_{r 1}=0.25 c_{n}$. (b) $c_{r 1}=0.5 c_{n}$.

$\mathrm{SW}_{2}$ after the BPC remanufacturer quits the market. And, the social welfare in the monopoly market is the sum of the manufacturer's profit $\left(\prod_{1}\right)$, consumer surplus $(\mathrm{CS})$, and environmental pollution $(E)$ :

$$
\mathrm{SW}_{2}=\Pi_{1}+\mathrm{CS}-E .
$$

We assume that both new and remanufactured products have an environmental impact. Each new production unit's environmental impact is $\varepsilon_{n}$; the manufacturer's remanufactured product has high quality. Its environmental impact factor is $\varepsilon_{r 1}$; the remanufactured products from BPC remanufacturer have low quality, and its environmental impact factor is $\varepsilon_{r 2}$.

According to the characteristics of the BPC company, we make the following assumptions. First, due to the remanufacturer's backward production technology level, the cost incurred in the re-production process must be higher than the manufacturer does, that is, $c_{r 2}>c_{r 1}$; (2) the energy consumption of this firm is higher, so its environmental pollution is higher: $\varepsilon_{r 2}>\varepsilon_{r 1}$.

Thus, the total environmental pollution can be expressed as 


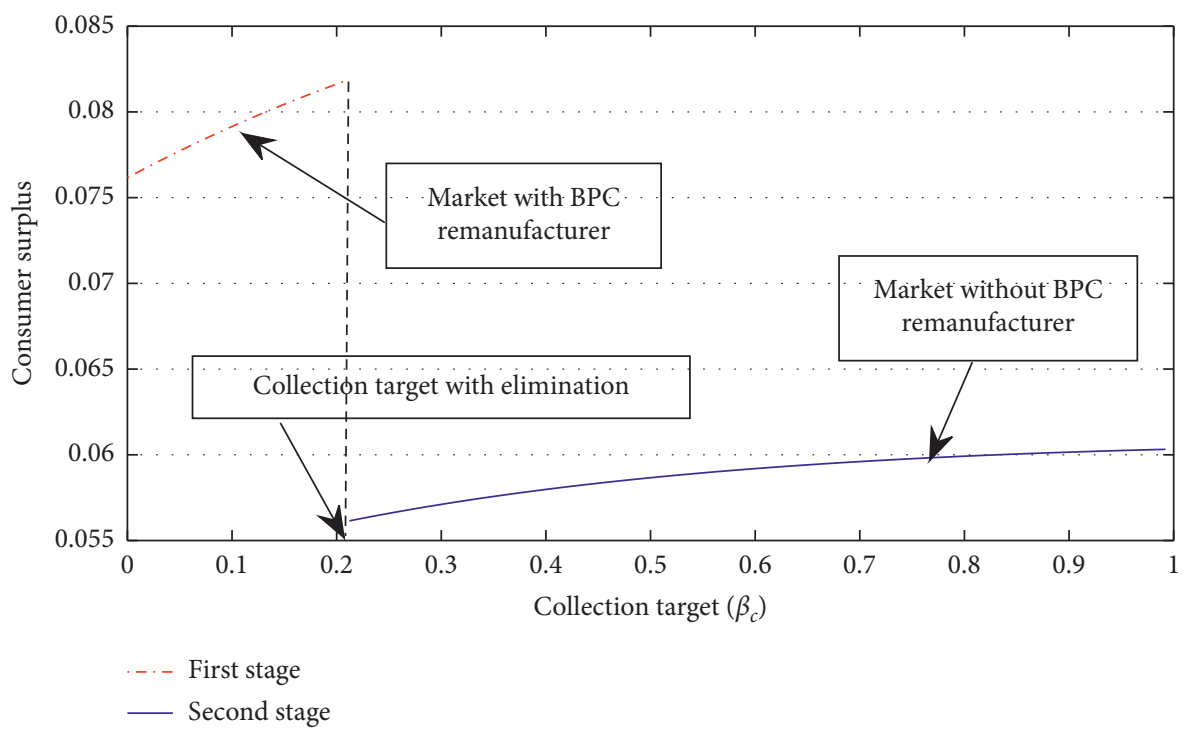

FIgURE 8: Consumer surplus under different strategies from the BPC remanufacturer.

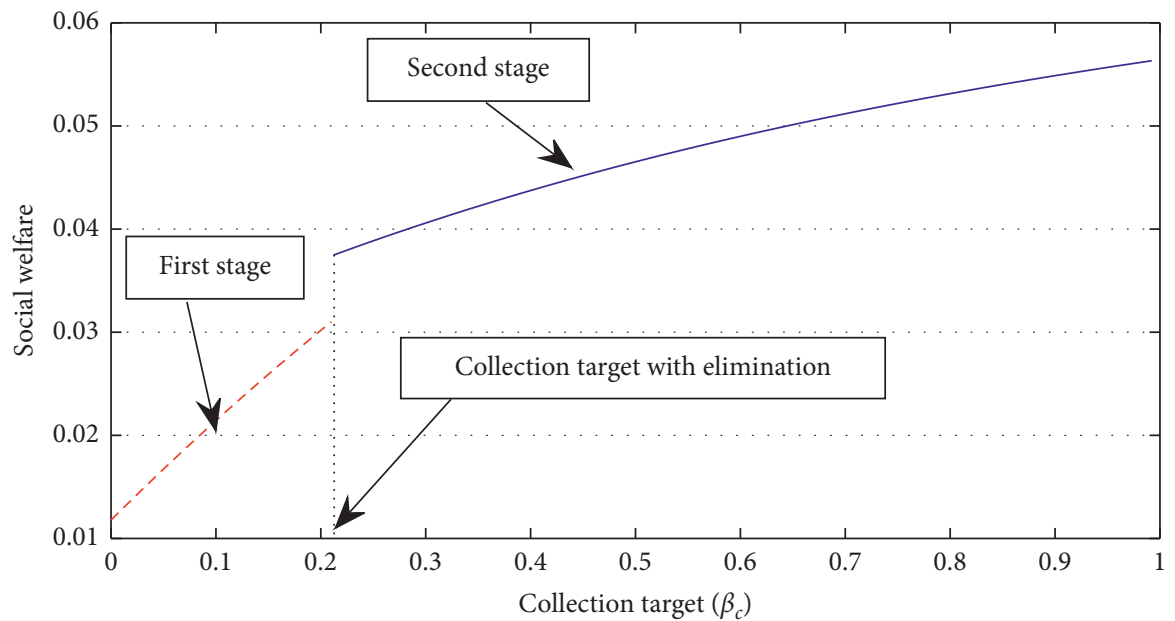

FIGURE 9: Change in social welfare as collection target increases.

$$
E=\varepsilon_{n} q_{n}+\varepsilon_{r 1} q_{r 1}+\varepsilon_{r 2} q_{r 2}
$$

It is analytically intractable to describe how social welfare changes concerning the collection target. Hence, we use a numerical study to observe how social welfare behaves as the collection target changes. Besides, for the parameters above, we choose $\varepsilon_{n}=0.4, \varepsilon_{r 1}=0.2$, and $\varepsilon_{r 2}=0.3$ to represent the problem we described before.

In our numerical study, we have observed that the BPC remanufacturer's profit always declines. Furthermore, the manufacturer's profit can increase all the time, except under certain conditions when his remanufacturing cost is high. Moreover, consumer surplus will come across a decline when the market turns to be a monopoly market. For demonstration, we present an example in Figure 9 to show how social welfare changes when the collection target increases and the market changes. Observe that, as the collection target increase, social welfare increases faster in the first stage (competitive market), changing from 0.011 to
0.031. This change is because the collection target regulates the manufacturer's behavior and affects BPC remanufacturer's decision. As the collection target gets higher and higher, remanufactured products from the BPC remanufacturer turn less, causing less environmental pollution and benefiting social welfare. After the BPC remanufacturer was eliminated, social welfare rises immediately, from 0.031 to 0.038. Because there are no low quality and high environmental pollution remanufactured products from BPC remanufacturers, environmental benefits have been improved, and his profit increases. Social welfare still increases with the collection target in the monopoly market, but its growing speed becomes slow. It is understandable because the manufacturer needs to complete a high collection target and his enthusiasm for production decreases with the increase of the collection target. When the manufacturer's remanufacturing cost is high, the manufacturer's decreasing profit will become an obstacle to the increasing social welfare. We summarize these observations as follows. 
TABLE 5: Objectives in each collection target interval.

\begin{tabular}{|c|c|c|c|c|}
\hline Objectives & $\left(0, \beta_{c}^{*}\right)$ & $\beta_{c}^{*}$ & $\left(\beta_{c}^{*}, 1\right)$ & 1 \\
\hline$\Pi_{1}$ & $\uparrow$ & Max & $\begin{array}{l}\text { If } c_{r 1} \text { is high: } \downarrow \\
\text { If } c_{r 1} \text { is low: } \uparrow\end{array}$ & - \\
\hline$\Pi_{2}$ & $\downarrow$ & 0 & - & - \\
\hline $\mathrm{CS}$ & $\uparrow$ & $\operatorname{Max}(\operatorname{Min})$ & $\uparrow$ & - \\
\hline SW & $\uparrow$ & $\uparrow$ & $\uparrow$ & $\uparrow$ \\
\hline
\end{tabular}

$\beta_{c}^{*}$ represents the collection target with elimination effect.

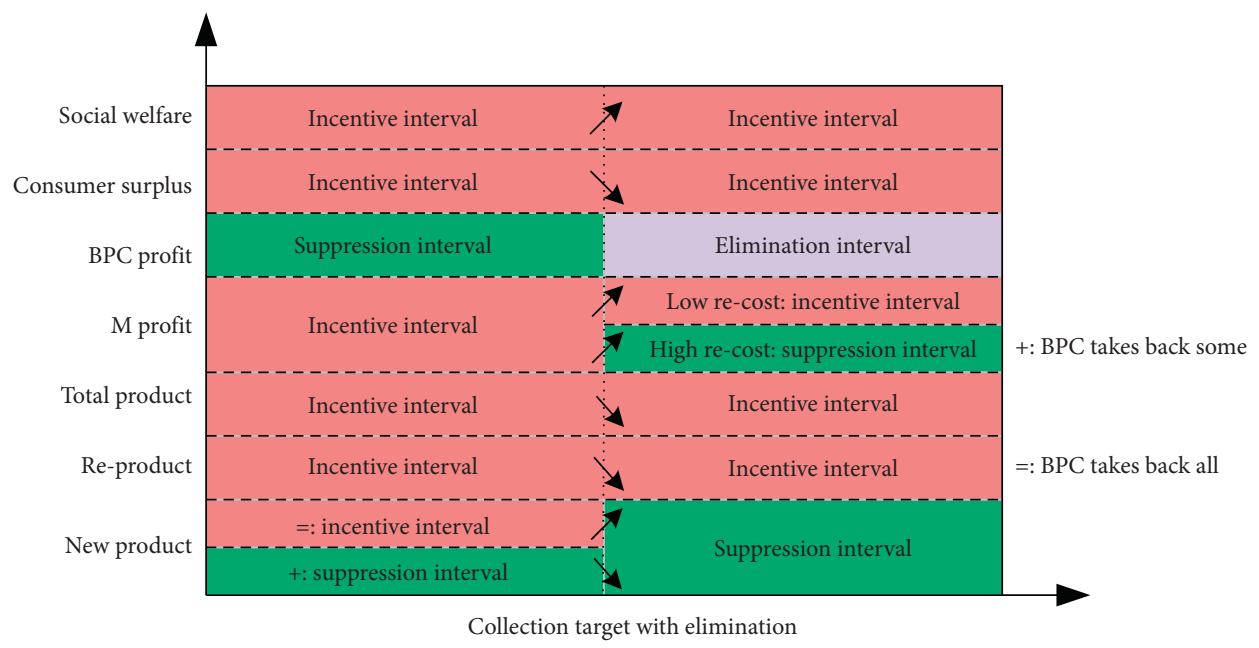

FIGURE 10: Summary of results.

Observation 2. The collection target with the elimination effect can improve social welfare. However, as the collection target increases, the incentive effect decreases.

To sum up all the observations and descriptions above, we can have the following table to show each collection target interval clearly.

As shown in Table 5, the collection target with the elimination effect can eliminate backward production capacity remanufacturer and maximize the profit. However, for consumers, the collection target with elimination effect may lead to their maximum utility in the competitive market but minimum utility in the monopoly market. From this, we can also see that consumers are more inclined to a competitive market. But for social welfare, the higher the collection target, the better.

\section{Conclusions and Remarks}

6.1. Conclusions and Answers to Research Questions. This paper develops a competition model to discuss the regulated collection target with the first stage's elimination effect. In particular, we focus on the changes from each perspective, after backward production capacity remanufacturer was eliminated by regulation. To verify our conclusions, we extended a discussion that the backward production capacity remanufacturer may choose a different take-back strategy.

Given the manufacturer's behavior and backward production capacity remanufacturer's activities, the government must understand the consequences of the collection target with the elimination effect. In Figure 10, we summarize our results to show how the collection target with the elimination effect affects each party. Moreover, we divide the collection target interval into two intervals to present the first stage (competitive market) and the second stage (monopoly market). However, the collection target plays different roles for each party in different intervals.

As a concluding remark, we give out our answers to the research questions:

(1) From our analysis, the take-back regulation imposed on the manufacturer may have an elimination effect on the BPC remanufacturer when the collection target exceeds a threshold. The government can clear the backward production capacity remanufacturer in the market by raising the collection target.

(2) We find that two-period collection targets are incentive intervals for remanufactured products and total products. In each interval, the number of remanufactured products and the total quantity can always increase with the collection target. However, when the elimination effect happens, the production of both types of products will decline. For new products, if the BPC firm chooses to take back all the EOL products in the market, this interval of collection target in the first stage is an incentive interval. Moreover, new products will increase as long as the market turns to the second stage. Otherwise, this interval of the collection target is a suppression interval, and the new product will decrease as long as the market turns to the second stage. In the second 
stage, the collection target interval is a suppression interval, which means new products will decrease with the collection target. These results imply that the collection target can regulate product structure in the market, and a high collection target will make the manufacturer lose enthusiasm for manufacturing new products. In fact, in real life, compared with remanufactured products, new products often occupy more market shares in the market.

(3) Our results show that, in the first stage, the interval of the collection target is a suppression interval for BPC remanufacturer. However, this interval can benefit the manufacturer, consumer, and government. Nevertheless, when the market enters the second stage, the BPC remanufacturer has been eliminated, and the manufacturer's profit will not always increase with the collection target. Thus, the interval of the collection target in this period is an elimination interval for BPC remanufacturers. This interval could be a suppression interval for the manufacturer if its remanufacturing cost is high. For consumers and the government, the second stage's collection target's interval still has an incentive effect. However, we should notice that consumer surplus has fallen to a minimum value as long as the BPC remanufacturer is eliminated. So, we know that, although the interval in the second stage is an incentive interval, this interval is not friendly to consumers compared to the first stage.

(4) The strategy of BPC remanufacturer can affect the structure of the market in the competitive market. If BPC remanufacturer chose to take back all rest of EOL products, the new products' output and remanufactured products are relatively steady. Otherwise, the new products' output (remanufactured products) will decrease (increase) with the collection target. And, the total quantity in the market will increase concerning the collection target. However, the take-back regulation's elimination effect will not disappear, even if the BPC remanufacturer adopted a different take-back strategy.

(5) Social welfare increases with the collection target all the time, which means that, from a holistic, the manufacturer's profit increases more than offsets the decrease in the surplus of consumer and profit of $\mathrm{BPC}$ remanufacturer.

6.2. Limitations and Future Studies. Finally, our research still has some limitations. First, we only consider one-to-one competition in the market. In practice, many manufacturers and remanufacturers are competing in the same market. Second, in our study, we focus on how take-back regulation (collection target) could serve as a regulator to eliminate the BPC remanufacturer. However, we do not consider the situation where multiple regulations coexist. For example, the government imposes the collection target on manufacturers and taxes on remanufacturers. For further studies, the cooperation between the manufacturer and the remanufacturer is impressive, especially when the take-back regulation gets strict. Another probable research direction is the diversity of reuse methods, such as dismantling. In practice, remanufactured products usually can be sold at an excellent price, but the output is insufficient. Manufacturers can dismantle some collected products and sell product components because they always have a high demand in the market, though their price may be a little lower. Finally, it is also interesting to extend the study to cover the impact of supply chains.

\section{Appendix}

Proof of Proposition 1. The first stage: there is a competitive relationship between the manufacturer and BPC remanufacturer. However, the manufacturer dominates the market. The BPC remanufacturer makes take-back and remanufacturing decisions based on the manufacturer's production decisions. Therefore, we use the Stackelberg game to solve the problem in the first stage. Under the take-back regulation asking the manufacturer to take back a certain percentage of EOL products, when the BPC remanufacturer's profit drops to 0 or the optimal take-back quantity of EOL products is 0 , it will exit the market.

This paper only analyzes the manufacturer taking back the minimum standard of take-back regulation to fulfill his responsibility. Otherwise, the take-back regulation will not work when the manufacturer tries to take back more than asked or take back all EOL products in the market. Thus, we can have $q_{r 1}=\beta_{c} q_{n}$. The parts that the manufacturer has not taken back will be taken back and remanufactured by the BPC remanufacturer $q_{r 2}=\left(1-\beta_{c}\right) q_{n}$. Moreover, we list the manufacturer's profit function and BPC remanufacturer's profit function as follows:

$$
\begin{array}{ll}
\underset{q_{n}, q_{r 1}}{\operatorname{Max}} & \Pi_{1}=\left(p_{n}-c_{n}\right) q_{n}+\left(p_{r}-c_{r 1}\right) q_{r 1} \\
\text { s.t. } & \beta_{c} q_{n} \leq q_{r 1} \leq q_{n}, \\
\underset{q_{r 2}}{\operatorname{Max}} & \Pi_{2}=\left(p_{r}-c_{r 2}\right) q_{r 2} \\
\text { s.t. } & 0 \leq q_{r 2} \leq q_{n}-q_{r 1} .
\end{array}
$$

According to the decision order of the Stackelberg game, we adopt a reverse-order solution method. First, we analyze the optimal production decision of BPC remanufacturer $\left(\Pi_{2}\right)$. For the profit function of BPC remanufacturer, we construct a Lagrangian function:

$$
L=\Pi_{2}-\lambda_{1}\left(q_{r 2}\right)-\lambda_{2}\left(q_{n}-q_{r 1}-q_{r 2}\right) .
$$

The KKT condition of the function $L$ is as follows: 


$$
\left\{\begin{array}{l}
\frac{\partial L}{\partial q_{r 2}}=-c_{r 2}-q_{r 2} \alpha+\alpha\left(1-q_{n}-q_{r 2}-q_{n} \beta_{c}\right)-\lambda_{1}+\lambda_{2}=0 \\
\lambda_{1}\left(q_{r 2}\right)=0 \\
\lambda_{2}\left(q_{n}-q_{r 1}-q_{r 2}\right)=0 .
\end{array}\right.
$$

Because the BPC remanufacturer will not choose the output as 0 by himself $\left(q_{r 2} \neq 0\right)$, we solve the KKT in the following two cases:

(a) $\lambda_{1}=0, \lambda_{2}>0$ : at this time, we can get $q_{r 2}=q_{n}-q_{n} \beta_{c}$ and $\lambda_{2}=c_{r 2}-\alpha+3 q_{n} \alpha-q_{n} \alpha \beta_{c}$. Because $\lambda_{2}>0$, we can easily have $\beta_{c}<3-\left(\left(\alpha-c_{r 2}\right) / \alpha q_{n}\right)$.

(b) $\lambda_{1}=0, \lambda_{2}=0$ : we can solve the formulation and get the optimal production decision of BPC remanufacturer: $q_{r 2}=\left(\left(-c_{r 2}+\alpha-q_{n} \alpha-q_{n} \alpha \beta_{c}\right) / 2 \alpha\right)$.

Next, we bring the results of two cases into the manufacturer's profit function $\left(\Pi_{1}\right)$ to solve the manufacturer's optimal production decision.

(1) If $q_{r 2}=q_{n}-q_{n} \beta_{c}$, it means the BPC remanufacturer collects and reuses all rest EOL products in the market, we let $\left(\partial \Pi_{1} / \partial q_{n}\right)=0$ and we can get the optimal value of the new product: $q_{n 1}^{*}=\left(\left(1-c_{n}-c_{r 1} \beta_{c}+\alpha \beta_{c}\right) /\left(2\left(1+\alpha+2 \alpha \beta_{c}\right)\right)\right)$; meanwhile, the optimal collection decision is $\beta_{c} q_{n 1}^{*}$.

(2) If $q_{r 2}=\left(\left(-c_{r}+\alpha-q_{n} \alpha-q_{n} \alpha \beta_{c}\right) / 2 \alpha\right)$, which means BPC remanufacturer collects and reuses part of rest EOL products in the market, we let $\left(\partial \Pi_{1} / \partial q_{n}\right)=0$ and we can have the optimal value of the new product: $\quad q_{n 2}^{*}=\left(\left(2-2 c_{n}+c_{r 2}-\alpha-2 c_{r 1} \beta_{c}+\right.\right.$ $\left.\left.c_{r 2} \beta_{c}+\alpha \beta_{c}\right) /\left(2\left(2-\alpha+2 \alpha \beta_{c}+\alpha \beta_{c}^{2}\right)\right)\right) ; \quad$ meanwhile, the optimal collection decision is $\beta_{c} q_{n 2}^{*}$.
Proof of Proposition 2. According to the proof of Proposition 1, we put the new product's optimal value into the formulation $q_{r 2}$ to solve the BPC remanufacturer's optimal production decision:

(1) If $q_{r 2}=q_{n}-q_{n} \beta_{c}, q_{r 2}^{*}=\left(1-\beta_{c}\right)\left(\left(1-c_{n}-c_{r 1} \beta_{c}+\right.\right.$ $\left.\left.\alpha \beta_{c}\right) /\left(2\left(1+\alpha+2 \alpha \beta_{c}\right)\right)\right)$

(2) If $q_{r 2}=\left(\left(-c_{r}+\alpha-q_{n} \alpha-q_{n} \alpha \beta_{c}\right) / 2 \alpha\right) ; \quad q_{r 2}^{*}=((\alpha-$ $\left.\left.c_{r}\right) / 2 \alpha\right)-\left(1+\beta_{c}\right)\left(\left(2-2 c_{n}+\quad c_{r 2}-\alpha+\left(c_{r 2}+\alpha-\right.\right.\right.$ $\left.\left.\left.2 c_{r 1}\right) \beta_{c}\right) /\left(4\left(2-\alpha+2 \alpha \beta_{c}+\alpha \beta_{c}^{2}\right)\right)\right)$

Proof of Proposition 3. From the proof above, we can know that there are two take-back strategies of BPC remanufacturer. One is taking back all the rest of EOL products, and the other is taking back part of the rest of EOL products. However, when the BPC remanufacturer chooses to take back part of the EOL products, it is hard to give out the following sections' analytical expression. So, in the following propositions, we consider that the BPC remanufacturer will adopt the first strategy, taking back all EOL products. As for the other take-back strategy, we will investigate it as an extended discussion in the numerical study section.

While the BPC remanufacturer decides to take back all rest of EOL products in the market, its quantity of taking back items must be greater than zero at this time. There are two main measures: the first is to set the collection target $\beta_{c}=1$, making BPC remanufacturer impossible to take back. However, a too high collection target will make the manufacturer bear more responsibilities, which is not conducive to his production enthusiasm. Although this method is the most straightforward and direct, it cannot be used in real life. Second, when the BPC remanufacturer's profit is less than (or equal to) zero, he will naturally be eliminated from the market. Through Propositions 1 and 2, we can conclude that the profit of the BPC remanufacturer at this time is

$$
\Pi_{2}=\frac{\left(\beta_{c}-1\right)\left(c_{n}-1+\left(c_{r 1}-\alpha\right) \beta_{c}\right)\left(-c_{r 2}\left(1+\alpha+2 \alpha \beta_{c}\right)+\alpha\left(c_{n}+\alpha+\left(c_{r 1}+\alpha\right) \beta_{c}\right)\right)}{2\left(1+\alpha+2 \alpha \beta_{c}\right)^{2}},
$$

where $\quad\left(\beta_{c}-1\right)\left(c_{n}-1+\left(c_{r 1}-\alpha\right) \beta_{c}\right)>0 \quad$ and $\quad 2(1+\alpha+$ $\left.2 \alpha \beta_{c}\right)^{2}>0$.

We rewrite $-c_{r 2}\left(1+\alpha+2 \alpha \beta_{c}\right)+\alpha\left(c_{n}+\alpha+\left(c_{r 1}+\alpha\right) \beta_{c}\right)$ as follows:

$$
g\left(\beta_{c}\right)=\alpha\left(c_{n}+\alpha\right)-(1+\alpha) c_{r 2}+\alpha \beta_{c}\left(c_{r 1}+\alpha-2 c_{r 2}\right) .
$$

If and only if $g\left(\beta_{c}\right) \leq 0$, then $\Pi_{2} \leq 0$, that is, there is no profit for BPC remanufacturer. From this, we get the following:
(1) If $c_{r 2}>\left(\left(c_{r 1}+\alpha\right) / 2\right)$ and $c_{r 2}>\left(\left(\alpha\left(c_{n}+\alpha\right)\right) /(1+\alpha)\right)$, the collection target always has an elimination effect.

(2) If $c_{r 1}<c_{r 2}<\left(\left(c_{r 1}+\alpha\right) / 2\right)$ and $c_{r 2}<\left(\left(\alpha\left(c_{n}+\alpha\right)\right) /\right.$ $(1+\alpha))$, the collection target always has no elimination effect.

(3) If $c_{r 1}<c_{r 2}<\left(\left(c_{r 1}+\alpha\right) / 2\right)$ and $c_{r 2}>\left(\left(\alpha\left(c_{n}+\alpha\right)\right) /\right.$ $(1+\alpha))$, there exists a $\beta_{c}^{+}$, when $\beta_{c} \geq \beta_{c}^{+}$and $g\left(\beta_{c}\right) \leq 0$.

(4) If $c_{r 2}>\left(\left(c_{r 1}+\alpha\right) / 2\right)$ and $c_{r 2}<\left(\left(\alpha\left(c_{n}+\alpha\right)\right) /(1+\alpha)\right)$, while the collection target meets $\beta_{c} \leq \beta_{c}^{+}$, we can have 
$g\left(\beta_{c}\right) \leq 0$. Where $\beta_{c}^{+}=\left(\left(\alpha\left(c_{n}+\alpha\right)-(1+\alpha) c_{r 2}\right) /\right.$ $\left.\left(2 c_{r 2}-\alpha-c_{r 1}\right)\right)$.

Proof of Proposition 4. When there is only one manufacturer in the market producing new and remanufactured products, the new market's counter-demand function becomes $p_{n}^{\prime}=1-q_{n}^{\prime}-\alpha q_{r}^{\prime} ; p_{r}^{\prime}=\alpha\left(1-q_{n}^{\prime}-q_{r}^{\prime}\right)$. When the manufacturer takes back EOL products following the collection target $q_{r}^{\prime}=\beta_{c} q_{n}^{\prime}$, the profit of the manufacturer can be expressed as follows:

$$
\Pi^{\prime}=\left(p_{n}^{\prime}-c_{n}\right) q_{n}^{\prime}+\left(p_{r}^{\prime}-c_{r 1}\right) q_{r}^{\prime} .
$$

We make $\left(\partial \Pi^{\prime} / \partial q_{n}^{\prime}\right)=0$, and we can get the optimal production decision of new product as $q_{n}{ }^{*}=\left(\left(1-c_{n}-c_{r 1} \beta_{c}+\alpha \beta_{c}\right) /\left(2+2 \alpha \beta_{c}\left(2+\beta_{c}\right)\right)\right)$.

Proof of Proposition 5. According to the result, we calculate in Propositions 1 and 4, when the BPC remanufacturer chooses to take back all rest of EOL products in the market, the number of new products in a competitive market and monopoly market is as follows:

$$
\begin{aligned}
q_{n 1}^{*} & =\frac{1-c_{n}-c_{r 1} \beta_{c}+\alpha \beta_{c}}{2\left(1+\alpha+2 \alpha \beta_{c}\right)}, \\
q_{n}^{\prime *} & =\frac{1-c_{n}-c_{r 1} \beta_{c}+\alpha \beta_{c}}{2+2 \alpha \beta_{c}\left(2+\beta_{c}\right)} .
\end{aligned}
$$

We compare the quantity of two stages of the new product, and we find that the two formulas have the same numerator, but $2\left(1+\alpha+2 \alpha \beta_{c}\right)>2+2 \alpha \beta_{c}\left(2+\beta_{c}\right)$. So, we have a conclusion that the quantity of new products in the second stage is higher than in the first stage.

Proof of Proposition 6. We know that the quantity of remanufactured products in the first stage is the number of new products in the first stage, while the quantity of remanufactured products in the second stage is $\beta_{c} q_{n}{ }^{*}$.
According to the calculation of Proposition 5, we compare the quantity of the two-stage remanufactured products:

$$
\begin{aligned}
\Delta q_{r}(1) & =q_{n}^{*}-\beta_{c} q_{n}^{*} \\
& =\frac{\left(1-\beta_{c}\right)\left(\left(1-c_{n}\right)+\left(\alpha-c_{r 1}\right) \beta_{c}\right)\left(1+\alpha \beta_{c}\right)}{2\left(1+\alpha+2 \alpha \beta_{c}\right)\left(1+\alpha \beta_{c}\left(2+\beta_{c}\right)\right)}>0 .
\end{aligned}
$$

where $\left(1-c_{n}\right)$ indicates the new product's competitive market advantage and $\left(\alpha-c_{r 1}\right)$ indicates the competitive market advantage of remanufactured products. These two factors should satisfy the relationship that $\left(1-c_{n}\right)>0$ and $\left(\alpha-c_{r 1}\right)>0$. Therefore, we can know that the quantity of remanufactured products in the first stage is higher than in the second stage.

Proof of Proposition 7. According to the calculation in Proposition 2, we can quickly get the manufacturer's profit formulation in the first stage: $\Pi_{1}^{*}=\left(\left(\left(-1+c_{n}+c_{r 1} \beta_{c}-\alpha \beta_{c}\right)^{2}\right) /\left(4\left(1+\alpha+2 \alpha \beta_{c}\right)\right)\right) ; \quad$ and according to Proposition 4 , we can get the manufacturer's profit formulation in the second stage: $\Pi_{1}^{\prime}{ }^{*}=\left(\left(\left(-1+c_{n}+c_{r 1} \beta_{c}-\alpha \beta_{c}\right)^{2}\right) /\left(4+4 \alpha \beta_{c}\left(2+\beta_{c}\right)\right)\right)$. We compare these two profits as follows:

$$
\Delta \Pi=\Pi_{1}^{*}-\Pi_{1}^{*}=-\frac{\alpha\left(-1+c_{n}+c_{r 1} \beta_{c}-\alpha \beta_{c}\right)^{2}\left(1-\beta c^{2}\right)}{4\left(1+\alpha+2 \alpha \beta_{c}\right)\left(1+\alpha \beta_{c}\left(2+\beta_{c}\right)\right)} \leq 0
$$

It can be seen that, under the collection target with elimination effect, the manufacturer can obtain higher profits in the second stage of the monopoly market. That is, the collection target with an elimination effect can improve the benefits of the manufacturer.

Proof of Proposition 8. Based on the calculation of Propositions 1 and 2, we can get the total consumer surplus of new products and remanufactured products in the first stage as

$$
\mathrm{CS}_{1}=\int_{\left(p_{n}-p_{r} / 1-\alpha\right)}^{1}\left(v-p_{n}\right) \mathrm{d} v+\int_{p_{r} / \alpha}^{\left(p_{n}-p_{r} / 1-\alpha\right)}\left(\alpha v-p_{r}\right) \mathrm{d} v=\frac{(1+3 \alpha)\left(-1+c_{n}+c_{r 1} \beta_{c}-\alpha \beta_{c}\right)^{2}}{8\left(1+\alpha+2 \alpha \beta_{c}\right)^{2}}
$$


According to Proposition 4, we can get the total consumer surplus of new products and remanufactured products in the second stage as

$$
\mathrm{CS}_{2}=\int_{\left(p_{n}-p_{r} / 1-\alpha\right)}^{1}\left(v-p_{n}\right) \mathrm{d} v+\int_{p_{r} / \alpha}^{\left(p_{n}-p_{r} / 1-\alpha\right)}\left(\alpha v-p_{r}\right) \mathrm{d} v=\frac{\left(-1+c_{n}+c_{r 1} \beta_{c}-\alpha \beta_{c}\right)^{2}}{8\left(1+\alpha \beta_{c}\left(2+\beta_{c}\right)\right)}
$$

By comparing the consumer surplus in the two stages, we have

$$
\begin{aligned}
\Delta \mathrm{CS} & =\mathrm{CS}_{1}-\mathrm{CS}_{2} \\
& =\frac{(1-\alpha) \alpha(1-\beta c)^{2}\left(-1+c_{n}+c_{r 1} \beta_{c}-\alpha \beta_{c}\right)^{2}}{8\left(1+\alpha+2 \alpha \beta_{c}\right)^{2}\left(1+\alpha \beta_{c}\left(2+\beta_{c}\right)\right)}>0 .
\end{aligned}
$$

From this, we know that the collection target with elimination effect will reduce consumer surplus.

\section{Data Availability}

The data used to support the findings of this study are included within the article.

\section{Conflicts of Interest}

The authors declare that they have no conflicts of interest.

\section{Acknowledgments}

The work was supported by the Postgraduate Research and Practice Innovation Program of Jiangsu Province (Project no. KYCX19_0144).

\section{References}

[1] USITC, Remanufactured Goods: U.S. Activities, Sector Studies, and Global Markets. Remanufactured Goods U.S. Act. Sect. Stud. Glob. Mark.USITC, Washington, DC, USA, 2013.

[2] Y. Chen, B. Li, Q. Bai, and Z. Liu, "Decision-making and environmental implications under cap-and-trade and takeback regulations," International Journal of Environmental Research and Public Health, vol. 15, no. 4, p. 678, 2018.

[3] J. Crotty, "Greening the supply chain? the impact of take-back regulation on the UK automotive sector," Journal of Environmental Policy and Planning, vol. 8, no. 3, 2006.

[4] G. Esenduran, E. Kemahlığlu-Ziya, and J. M. Swaminathan, "Take-back legislation: consequences for remanufacturing and environment," Decision Sciences, vol. 47, no. 2, pp. 219-256, 2016.

[5] G. Esenduran, E. Kemahlıoğlu-Ziya, and J. M. Swaminathan, "Product take-back legislation and its impact on recycling and remanufacturing industries," International Series in Operations Research and Management Science, Springer, New York, NY, USA, 2012.

[6] T. Lindhqvist, Extended Producer Responsibility in Cleaner Production-Policy Principle to Promote Environmental Improvements of Product Systems, Lund University, Lund, Sweden, 2000.
[7] G. Esenduran, E. Kemahlığlu-Ziya, and J. M. Swaminathan, "Impact of take-back regulation on the remanufacturing industry," Production and Operations Management, vol. 26, no. 5, pp. 924-944, 2017.

[8] European Commission, Directive of the European Parliament [WWW Document], European Commission, Brussels, Belgium, 2008, http://ec.europa.eu/environment/waste/weee/ index_en.htm.

[9] A. Atasu, Ö. Ö asuva, and L. N. Van Wassenhove, "Stakeholder perspectives on e-waste take-back legislation," Production and Operations Management, vol. 22, no. 2, pp. 382-396, 2013.

[10] Y. Wang, B. Xin, Z. Wang, and B. Li, "Managing suppliermanufacturer closed-loop supply chain considering product design and take-back legislation," International Journal of Environmental Research and Public Health, vol. 16, no. 4, p. 623, 2019.

[11] X. Chang, J. Wu, T. Li, and T.-J. Fan, “The joint tax-subsidy mechanism incorporating extended producer responsibility in a manufacturing-recycling system," Journal of Cleaner Production, vol. 210, pp. 821-836, 2019.

[12] X. Gao, H. Zheng, Y. Zhang, and N. Golsanami, "Tax policy, environmental concern and level of emission reduction," Sustainability, vol. 11, no. 4, Article ID 1047, 2019.

[13] G. Esenduran and E. Kemahlıŏlu-Ziya, "A comparison of product take-back compliance schemes," Production and Operations Management, vol. 24, no. 1, pp. 71-88, 2015.

[14] W. Chen, B. Kucukyazici, and M. J. Saenz, "On the joint dynamics of the economic and environmental performances for collective take-back systems," International Journal of Production Economics, vol. 218, pp. 228-244, 2019.

[15] I. Konstantaras, "Optimal control of production and remanufacturing in a reverse logistics model with backlogging," Mathematical Problems in Engineering, vol. 2010, Article ID 320913, 19 pages, 2010.

[16] Z. Li, J. Zhang, Q. Meng, W. Zheng, and J. Du, "Influence of government subsidy on remanufacturing decision under different market models," Mathematical Problems in Engineering, vol. 2019, Article ID 9460315, 16 pages, 2019.

[17] Z. Liu, J. Tang, B.-y. Li, and Z. Wang, "Trade-off between remanufacturing and recycling of WEEE and the environmental implication under the Chinese fund policy," Journal of Cleaner Production, vol. 167, pp. 97-109, 2017.

[18] X. Long, J. Ge, T. Shu, and Y. Liu, "Analysis for recycling and remanufacturing strategies in a supply chain considering consumers' heterogeneous WTP," Resources, Conservation and Recycling, vol. 148, pp. 80-90, 2019.

[19] M. Ullah and B. Sarkar, "Recovery-channel selection in a hybrid manufacturing-remanufacturing production model with RFID and product quality," International Journal of Production Economics, vol. 219, pp. 360-374, 2020. 
[20] B. Wang and J. Wang, "Price and service competition between new and remanufactured products," Mathematical Problems in Engineering, vol. 2015, Article ID 325185, 18 pages, 2015.

[21] Z. Wang, B. Li, X. Zhu, B. Xin, and Y. Wang, "The impact of donation subsidy of remanufactured products on manufacturer's pricing-production decisions and performances," Journal of Cleaner Production, vol. 202, pp. 892-903, 2018.

[22] H. Stackelberg, Marktform und Gleichgewicht, Springer, Vienna, Austria, 1934

[23] Q. Feng and L. X. Lu, "Supply chain contracting under competition: bilateral bargaining vs. Stackelberg," Production and Operations Management, vol. 22, no. 3, pp. 661-675, 2013.

[24] M. W. Iqbal and B. Sarkar, "Recycling of lifetime dependent deteriorated products through different supply chains," RAIRO-Operations Research, vol. 53, no. 1, 2019.

[25] S. Liu and Z. Xu, "Stackelberg game models between two competitive retailers in fuzzy decision environment," Fuzzy Optimization and Decision Making, vol. 13, no. 1, pp. 33-48, 2014.

[26] J. Noh, J. S. Kim, and B. Sarkar, "Two-echelon supply chain coordination with advertising-driven demand under Stackelberg game policy," European Journal of Industrial Engineering, vol. 13, no. 2, pp. 213-244, 2019.

[27] B. Sarkar, R. Guchhait, M. Sarkar, S. Pareek, and N. Kim, "Impact of safety factors and setup time reduction in a twoechelon supply chain management," Robotics and ComputerIntegrated Manufacturing, vol. 55, pp. 250-258, 2019.

[28] A. A. Taleizadeh, M. Noori-Daryan, and K. Govindan, "Pricing and ordering decisions of two competing supply chains with different composite policies: a Stackelberg gametheoretic approach," International Journal of Production Research, vol. 54, no. 9, pp. 2807-2836, 2016.

[29] J. Cao, X. Zhang, L. Hu et al., "EPR regulation and reverse supply chain strategy on remanufacturing," Computers \& Industrial Engineering, vol. 125, pp. 279-297, 2018.

[30] S. Webster and S. Mitra, "Competitive strategy in remanufacturing and the impact of take-back laws," Journal of Operations Management, vol. 25, no. 6, pp. 1123-1140, 2007.

[31] G. Ferrer and J. M. Swaminathan, "Managing new and differentiated remanufactured products," European Journal of Operational Research, vol. 203, no. 2, pp. 370-379, 2010.

[32] G. Ferrer and J. M. Swaminathan, "Managing new and remanufactured products," Management Science, vol. 52, no. 1, pp. 15-26, 2006.

[33] M. Kwak and H. Kim, "Design for life-cycle profit with simultaneous consideration of initial manufacturing and endof-life remanufacturing," Engineering Optimization, vol. 47, no. 1, pp. 18-35, 2015.

[34] W. Du and M. Li, "Can environmental regulation promote the governance of excess capacity in China's energy sector? the market exit of zombie enterprises," Journal of Cleaner Production, vol. 207, pp. 306-316, 2019.

[35] Y. Shao and S. Wang, "Productivity growth and environmental efficiency of the nonferrous metals industry: an empirical study of China," Journal of Cleaner Production, vol. 137, pp. 1663-1671, 2016.

[36] X. Wang, Y. Zhu, H. Sun, and F. Jia, "Production decisions of new and remanufactured products: implications for low carbon emission economy," Journal of Cleaner Production, vol. 171, pp. 1225-1243, 2018.

[37] Q. Tong, S. Zhou, Y. Guo, Y. Zhang, and X. Wei, "Forecast and analysis on reducing China's $\mathrm{CO}_{2}$ emissions from lime industrial process," International Journal of Environmental Research and Public Health, vol. 16, no. 3, p. 500, 2019.
[38] L. Zhang, Q. Shen, M. Wang et al., "Driving factors and predictions of $\mathrm{CO}_{2}$ emission in China's coal chemical industry," Journal of Cleaner Production, vol. 210, pp. 11311140, 2019.

[39] Z. Li, H. Dai, J. Song et al., "Assessment of the carbon emissions reduction potential of China's iron and steel industry based on a simulation analysis," Energy, vol. 183, pp. 279-290, 2019.

[40] Y.-L. Lü, J. Geng, and G.-Z. He, "Industrial transformation and green production to reduce environmental emissions: taking cement industry as a case," Advances in Climate Change Research, vol. 6, no. 3-4, pp. 202-209, 2015.

[41] X. Chen, B. Li, Z. Li, G. Mark, and S. Wei, "Take-back regulation policy on closed loop supply chains: single or double targets?" Journal of Cleaner Production, vol. 283, Article ID 124576, 2020.

[42] K. S. Moorthy, "Product and price competition in a duopoly," Marketing Science, vol. 7, no. 2, pp. 141-168, 1988.

[43] M. E. Ferguson and L. B. Toktay, "The effect of competition on recovery strategies," Production and Operations Management, vol. 15, no. 3, pp. 351-368, 2006.

[44] M. R. Galbreth, T. Boyac1, and V. Verter, "Product reuse in innovative industries," Production and Operations Management, vol. 22, no. 4, pp. 1011-1033, 2013.

[45] A. Örsdemir, E. Kemahlığlu-Ziya, and A. K. Parlaktürk, "Competitive quality choice and remanufacturing," Production and Operations Management, vol. 23, no. 1, pp. 48-64, 2014.

[46] A. Atasu, M. Sarvary, and L. N. Van Wassenhove, "Remanufacturing as a marketing strategy," Management Science, vol. 54, no. 10, pp. 1731-1746, 2008.

[47] B. W. Jacobs and R. Subramanian, "Sharing responsibility for product recovery across the supply chain," Production and Operations Management, vol. 21, no. 1, pp. 85-100, 2012.

[48] A. Ovchinnikov, V. Blass, and G. Raz, "Economic and environmental assessment of remanufacturing strategies for product + service firms," Production and Operations Management, vol. 23, no. 5, pp. 744-761, 2014. 